\title{
Lithospheric structure of Venus from gravity and topography
}

\author{
Alberto Jiménez-Díaz ${ }^{\text {a, b,* }}$, Javier Ruiz ${ }^{\text {a }}$, Jon F. Kirby ${ }^{\text {c }}$ \\ Ignacio Romeo $^{\text {a }}$, Rosa Tejero ${ }^{\text {a, b }}$, Ramón Capote ${ }^{\text {a }}$
}

${ }^{a}$ Departamento de Geodinámica, Facultad de Ciencias Geológicas, Universidad

Complutense de Madrid. 28040 Madrid, Spain

${ }^{\mathrm{b}}$ Instituto de Geociencias, IGEO (CSIC,UCM). 28040 Madrid, Spain

c Department of Spatial Sciences, Curtin University, GPO Box U1987, Perth WA 6845, Australia

* Corresponding author:

Alberto Jiménez-Díaz

Departamento de Geodinámica, Facultad de CC. Geológicas,

Universidad Complutense de Madrid.

c/ José Antonio Novais, 12. 28040 Madrid (Spain)

Tel: +34 91394 4821; Fax: +34 913944845 .

E-mail address: ajimenezdiaz@geo.ucm.es 


\begin{abstract}
There are many fundamental and unanswered questions on the structure and evolution of the Venusian lithosphere, which are key issues for understanding Venus in the context of the origin and evolution of the terrestrial planets. Here we investigate the lithospheric structure of Venus by calculating its crustal and effective elastic thicknesses ( $T_{c}$ and $T_{e}$, respectively) from an analysis of gravity and topography, in order to improve our knowledge of the large scale and long-term mechanical behaviour of its lithosphere. We find that the Venusian crust is usually 20-25 km thick with thicker crust under the highlands. Our effective elastic thickness values range between $14 \mathrm{~km}$ (corresponding to the minimum resolvable $T_{e}$ value) and $94 \mathrm{~km}$, but are dominated by low to moderate values. $T_{e}$ variations deduced from our model could represent regional variations in the cooling history of the lithosphere and/or mantle processes with limited surface manifestation. The crustal plateaus are near-isostatically compensated, consistent with a thin elastic lithosphere, showing a thickened crust beneath them, whereas the lowlands exhibit higher $T_{e}$ values, maybe indicating a cooler lithosphere than that when the Venusian highlands were emplaced. The large volcanic rises show a complex signature, with a broad range of $T_{e}$ and internal load fraction $(F)$ values. Finally, our results also reveal a significant contribution of the upper mantle to the strength of the lithosphere in many regions.
\end{abstract}

Keywords: Geophysics; Terrestrial planets; Venus; Venus, interior 


\section{Introduction}

Venus and the Earth share a similar size, nearly equivalent density and bulk composition, and close proximity to the Sun. Despite these similarities, Venus's tectonics and dynamic evolution are very different from those of the Earth. The Venusian lithosphere is stagnant and shows no evidence for present-day global plate tectonics (e.g., Solomon and Head, 1982; Solomon et al., 1992). Recent data provided from the Venus Express Mission show evidence of geologically young, and even ongoing, volcanism on the Venusian surface (Smrekar et al., 2010). However, the thermal history of Venus remains an enigma and there are many fundamental and unanswered questions on the structure and evolution of its lithosphere (e.g., Smrekar et al., 1997; Stofan et al., 1997; Phillips et al., 1997; Grimm and Hess, 1997), which are key issues for understanding Venus in the context of the origin and evolution of the terrestrial planets (Garvin et al., 2009; Ghail et al., 2012; Sotin et al., 2014; VEXAG, 2014).

The analysis of gravity and topography data provides useful constraints to solve many fundamental questions on the geodynamics of terrestrial planets, probing the structure and mechanical behaviour of their lithospheres, for example how they respond to loading and unloading (Wieczorek, 2007; Audet, 2011, 2014; Watts et al., 2013). In particular, a useful parameter that describes this behaviour is the effective elastic thickness $\left(T_{e}\right)$ of the lithosphere, which, in turn, can be used to constrain the thermal structure and evolution of a planetary body (e.g., Zuber et al., 2000; McGovern et al., 2002; Ruiz et al., 2011). $T_{e}$ is a proxy for the strength of the lithosphere, integrating contributions from brittle and ductile layers and from elastic cores of the lithosphere (for a review see Watts and Burov, 2003).

Although previous research provided important constraints on the effective 
elastic thickness of Venus (e.g., Johnson and Sandwell, 1994; Smrekar, 1994, Simons et al., 1994, 1997; McKenzie and Nimmo, 1997; Smrekar and Stofan, 1999; Barnett et al., 2000, 2002; Hoogenboom et al., 2004, 2005), work on global mapping of $T_{e}$ is very scarce. Anderson and Smrekar (2006) presented the first global map of $T_{e}$ for Venus based on the spatio-spectral localization technique of Simons et al. (1997) by using three end-member models of loading (top loading, bottom loading, or hot spot) and fitting their results to specified classes of results. Recently, Audet (2014) used a spherical wavelet analysis of gravity and topography and thin shell loading models, and presented preliminary mappings of $T_{e}$ for the Moon, Mars and Venus, in order to analyse both the promises and the limitations of fully spherical techniques.

Recent advances in joint spectral analysis of gravity and topography and improvements in lithospheric modelling of the Earth have led to mapping of $T_{e}$ at an unprecedented resolution (for reviews see Audet, 2014; Kirby, 2014). Given these recent methods developed for the Earth, it is a natural step to make a reliable $T_{e}$ map for Venus at high resolution. Performing this task would be of interest to re-evaluate regional variations in, and improve the characterization of, the structure and rheological behaviour of the lithosphere of this planet.

Thus, we have calculated maps of the spatial variations of Venusian $T_{e}$, as well as of their associated surface and subsurface loading mechanisms, from the analysis of the Bouguer coherence using a wavelet transform (Kirby and Swain, 2009, 2011), modelled with a simple thin elastic plate subject to both surface and subsurface loads, following the load deconvolution procedure of Forsyth (1985). We have performed our mapping in the Cartesian domain, dividing the surface of Venus into 36 overlapping areas (or 'tiles'). This procedure is useful: indeed, the radius of curvature of Venus is large enough for the elastic plate and shell formulations to produce equivalent 
coherence spectra for the expected range of $T_{e}$ values (see Audet, 2014). Also, Audet (2014) showed that the Cartesian analysis is robust over small regions if the data edges of the Cartesian grid are excluded. Prior to estimating $T_{e}$, we present a global model of crustal thickness, which is required for the lithospheric analysis, derived from topography and gravity. Finally, we discuss the implications of our results for the large scale and long-term evolution and behaviour of the Venusian crust and lithosphere.

\section{Global gravity and topography of Venus}

Gravity and topography data acquired by the Magellan spacecraft between 1990 and 1994 remain the most complete set for constraining the structure of the Venusian lithosphere. We apply potential theory to model the crustal thickness of Venus from the relationship between gravity and topography data (Section 3). This analysis has been developed in spherical coordinates making use of spherical harmonics. Thus, we use the spherical harmonic models SHTJV360u (Rappaport et al., 1999) and SHGJ180u (Konopliv et al., 1999) for topography and gravity respectively (available at http://pdsgeosciences.wustl.edu; see Fig.1).

While SHTJV360u and SHGJ180u are supplied to degree and order 360 and 180, respectively, the topography and gravity used in spectral flexural analyses must have the same bandwidth, because the coherence (and admittance) compares these data in the spectral domain. Therefore we expand the gravity and topography coefficients up to degree and order 180 only, which corresponds to a minimum wavelength of $\approx 211 \mathrm{~km}$ at the Venusian equator. This corresponds to a flexural wavelength such that the minimum resolvable $T_{e}$ is $\approx 14 \mathrm{~km}$ (estimated through $\lambda_{\text {flex }} \approx 29 T_{e}^{3 / 4}$; see Swain and Kirby, 2003), which is useful taking into account the limited data resolution and large errors in the gravity model (see Audet, 2014). However, we note that the accuracy of the 
SHGJ180u gravity data is quite low, with large uncertainties at spherical harmonics beyond 60-70 (see for example, Anderson and Smrekar, 2006; Wieczorek, 2007; James et al., 2013); we will return to this issue in the Results Section.

Effective elastic thickness modelling has been developed in the Cartesian domain by using a continuous planar wavelet analysis of gravity and topography data (see Section 4). Although Audet (2011, 2014) recently developed a continuous spherical wavelet transform for estimating $T_{e}$, he found that the differences between the spherical and planar methods were small ( $<10 \%$ of the absolute $T_{e}$ value) for Earth-size planets and concentrated at the data area edges (Audet, 2014). In order to reduce the effects of distortion from curvature of a planet's surface, we divide the surface of Venus into 36 overlapping areas (or 'tiles') from north to south and west to east (Fig. 2a), and project the gravity and topography in each of them to a Cartesian frame using an oblique Mercator map projection, providing a global coverage. Each tile has dimensions of 6000 km (easting) x $6000 \mathrm{~km}$ (northing), and a grid spacing of $20 \mathrm{~km}$ in both directions. The Bouguer gravity anomaly and topography are mirrored about their edges prior to Fourier transformation with the purpose of reducing leakage, which, when used with the wavelet transform, does not generally bias the results significantly (see Kirby and Swain, 2008, for a discussion on mirroring). The planar wavelet analysis for coherence and subsequent inversion for $T_{e}$ were then carried out on each tile. Inversions for $T_{e}$ and subsurface-to-surface load ratio ( $f$; see Section 4) were performed only on observed coherences with wavelengths $>211 \mathrm{~km}$ (accordingly, both gravity and topography data were truncated to degree and order 180 in our analysis; see above). After inversion, $T_{e}$ and $F$ data at the edges of each tile (10\% of a side length) were removed to mitigate possible remnant edge effects near the grid boundaries (see Fig. 2b). As a final step, $T_{e}$ and $F$ results were back-projected onto geographic $1^{\circ} \times 1^{\circ}$ grids, and merged and 
gridded using GMT’s 'surface’ algorithm (Smith and Wessel, 1990) to produce global $T_{e}$ and $F$ maps that combine the information from all tiles.

All maps are generated using GMT (Wessel et al., 2013), and are presented in Robinson projection with east-positive longitude convention and centred on $180^{\circ}$ longitude.

\section{Crustal thickness modelling}

We use the relationship between global topography and gravity data to model the crustal thickness $\left(T_{c}\right)$ of Venus following the potential theory procedure of Wieczorek and Phillips (1998), which was originally derived for estimating $T_{c}$ of the Moon and later used in other crustal thickness modelling of the Moon (Wieczorek, 2007), Mars (Zuber et al., 2000; Neumann et al., 2004; Wieczorek, 2007; Cheung and King, 2014), and Venus (Wieczorek, 2007; James et al., 2013). To constrain the thickness of the Venusian crust, we assume (1) that the observed gravitational anomalies arise only from a combination of surface topography and variations at the crust-mantle interface (i.e., the “Moho”), and (2) constant crustal and mantle densities to overcome the non-uniqueness associated with potential modelling. Under these assumptions, we first calculate the Bouguer gravity anomaly from surface topography and the free air anomaly, and then calculate by downward continuation the relief along the crust-mantle interface necessary to explain the observed Bouguer gravity anomaly (for reviews see Wieczorek and Phillips, 1998; Wieczorek, 2007). In order to mitigate errors in downward continuing the Bouguer anomaly, we applied a minimum amplitude filter (see Wieczorek and Phillips, 1998) for the Moho relief at degree $l=70$. Finally, we obtain the crustal thickness by subtracting the relief on the Moho from surface topography. 
Since we cannot constrain the crustal thickness model with a given value at a specific location on Venus (for example, by using the minimum $T_{c}$ at deep impact basins as Hellas or Isidis on Mars; e.g., Neumann et al., 2004), we assume a mean $T_{c}$ to "anchor" our model satisfying the condition that the inverted crustal thickness is not negative anywhere on the planet. Furthermore, the phase transition from basalt to dense eclogite limits large $T_{c}$ values such that they cannot result in crust anywhere extending below the basalt-eclogite phase change depth, predicted to occur at depths of $\sim 70-120$ km depending on the temperature gradient (e.g., Namiki and Solomon, 1993; Jull and Arkani-Hamed, 1995; Ghent et al., 2004). With these constraints, we assume an average crustal thickness of $25 \mathrm{~km}$ consistent with the range of 5-50 km obtained by previous studies (e.g., Zuber, 1987; Grimm, 1994; Phillips, 1994; Konopliv and Sjogren, 1994; Simons et al., 1994, 1997; Grimm and Hess, 1997).

The obtained global crustal thickness model is shown in Fig. 3a. Fig. 3b shows the gravity misfit (the difference between observed and calculated gravity), derived from the crustal thickness modelling, corresponding to the results in Fig. 3a and Fig. 4. The Venusian crust exhibits a good spatial correlation between topography and crustal thickness, with highland regions and crustal plateaus being locally thicker than the surrounding plains and lowland regions, and large volcanic rises characterized by intermediate to high $T_{c}$ values. The crustal thickness variation pattern agrees well with results of previous global crustal thickness modelling (Anderson and Smrekar, 2006; Wieczorek, 2007; James et al., 2013). Our model (which is based upon the premise of an average crustal thickness of $25 \mathrm{~km}$, and crust and mantle densities of, respectively, 2900 and $3300 \mathrm{~kg} \mathrm{~m}^{-3}$ ) finds a crustal thickness that varies from $\approx 10$ to $\approx 100 \mathrm{~km}$, with the smallest values associated with Atalanta, Sedna and Lavinia planitiae, while Lakshmi Planum and Maxwell Montes (which reach a maximum elevation of $11 \mathrm{~km}$ ) on 
Ishtar Terra are characterized by the higher values of $T_{c}$.

The global crustal structure is distinctly unimodal (Fig. 4a). It has one major peak at approximately 20-22 km, with a tail of values higher than the average crustal thickness of $25 \mathrm{~km}$, and with less than 20\% of crust being thinner than $20 \mathrm{~km}$. Pole-topole longitudinal transects of the crustal structure, as well as an equatorial transect (Fig. 4b,c), clearly show the thickening beneath the highland plateaus, and thin crust beneath the lowland plains, where the transition in thickness between highlands and lowlands is relatively abrupt. In general, the Moho relief gives the impression of a crust usually 20$25 \mathrm{~km}$ thick with superposition of thicker crust associated with the highlands. This suggests that most of the Venusian crust was emplaced under similar conditions, and different to those generating the crustal plateaus.

As mentioned above, some 'key' assumptions in the crustal thickness modelling may lead to significant changes in the obtained results; the most important of those assumptions is the density contrast between the mantle and crust, which affects to both the overall average crustal thickness and the amplitude of crustal variations in our model (see Neumann et al., 2004; Baratoux et al., 2014). Since the crust-mantle density contrast was constrained to be $400 \mathrm{~kg} \mathrm{~m}^{-3}$ in our analysis, the assumed average crustal thickness of $25 \mathrm{~km}$ plays the most important role in the crustal thickness distribution. In Fig. 5 we plot the minimum and maximum crustal thickness as a function of the average crustal thickness. We found that, as expected, extreme values increase with increasing average crustal thickness; also the amplitude of crustal variations increases slightly with the average crustal thickness.

\section{Estimating the effective elastic thickness of the lithosphere}

To estimate the effective elastic thickness we calculate the coherence function 
relating the topography and Bouguer anomaly (i.e., the Bouguer coherence) by using the wavelet transform (Kirby and Swain, 2009, 2011), modelled with a simple thin elastic plate subject to both surface and subsurface loads, following the load deconvolution procedure of Forsyth (1985). The Bouguer coherence gives information on the wavelength band over which topography and Bouguer anomaly are correlated, such that it generally tends to zero at short wavelengths, where the topography is not compensated and loads are supported predominantly by the elastic strength of the lithosphere (Forsyth, 1985). At long wavelengths, the response to loading approaches the Airy limit and the coherence tends to one. The wavelengths at which the coherence rapidly increases from 0 to 1 depend on the effective elastic thickness of the lithosphere, such that when the lithosphere is weak and $T_{e}$ is small, local compensation for loading occurs at relatively shorter wavelengths, and vice versa.

First, as mentioned in Section 2, we divide the gravity and topography data into 36 tiles, map-projected the data, and perform the following planar wavelet analysis on each tile. The wavelet coherence method convolves a range of scaled wavelets with the data under consideration to map and invert the coherence at each grid point, and achieves good wavenumber resolution over long length scales and good spatial resolution over short length scales. Here we employ a Morlet wavelet in the fan wavelet transform (Kirby and Swain, 2011). The wavelet coherence between the Bouguer gravity anomaly and topography is calculated from

$$
\gamma^{2}(\kappa, \mathbf{x})=\frac{\left|\left\langle B_{\kappa \times \theta} H_{\kappa \times 0}^{*}\right\rangle_{\theta}\right|^{2}}{\left\langle B_{\kappa \times \theta} B_{\kappa \times \theta}^{*}\right\rangle_{\theta}\left\langle H_{\kappa \times \theta} H_{\kappa \times \theta}^{*}\right\rangle_{\theta}},
$$

where $B$ and $H$ are the fan wavelet transform of the Bouguer gravity anomaly and 
topography, respectively. These are functions of spatial location (x), 2-D Morlet wavelet azimuth $(\theta)$, and wavelet scale (s), which may then be simply related to an equivalent Fourier wave number ( $\kappa$ ) by the relation $\kappa=\left|\mathbf{k}_{0}\right| / s$, where $\left|\mathbf{k}_{0}\right|$ is the central wave number of the Morlet wavelet (Kirby and Swain, 2011). The largest scale was chosen such that the longest equivalent Fourier wavelength was $6000 \mathrm{~km}$ (the side length of a tile); the smallest chosen scale corresponds approximately to the Nyquist wavelength of the gridded data $(40 \mathrm{~km})$, though we note that this is far less than the minimum wavelength of the data (211 km). The value of $\left|\mathbf{k}_{0}\right|$ governs the resolution of the wavelet in the space and wavenumber domains (Kirby and Swain, 2011). Large values of $\left|\mathbf{k}_{0}\right|$ give the Morlet wavelets a high wavenumber-domain resolution but poor space-domain resolution, while small values of $\left|\mathbf{k}_{0}\right|$ give a poorer wavenumber-domain resolution but better space-domain resolution (Kirby and Swain, 2011, 2013). The $\left|\mathbf{k}_{0}\right|$ value used in this study is 5.336, which has a good resolution in the wavenumber domain and a reasonably good resolution in the space domain (Kirby and Swain, 2011, 2013).

As shown by Kirby and Swain (2009), the coherence as given by equation (1) can sometimes be strongly biased by incoherent signals which manifest in the imaginary parts of the coherency. We follow Kirby and Swain (2009) and invert the squared real coherency (SRC) instead, because it is less sensitive to correlations between the initial loads on the plate and to the presence of topographically unexpressed internal loading (commonly known as "gravitational noise”), both of which can cause incorrect recovery of $T_{e}$ (e.g., McKenzie and Fairhead, 1997; McKenzie, 2003; Kirby and Swain, 2009; Audet and Bürgmann, 2011; Kirby, 2014). The complex wavelet coherency is given by

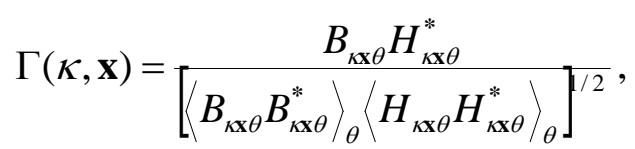


In the load-deconvolution method of Forsyth (1985), $T_{e}$ is estimated by comparing the observed coherence curve with coherence functions predicted for a range of $T_{e}$ values. Here we follow the same procedure but with SRCs instead of coherences (Kirby and Swain, 2009), and using wavelets rather than Fourier transforms (Swain and Kirby, 2006). Briefly, load deconvolution estimates the initial surface and subsurface loads from the observed gravity and topography, assuming a certain $T_{e}$ value. The predicted SRC (coherence) between these initial loads can be directly compared with the observed SRC (coherence) between observed gravity and topography, and $T_{e}$ varied until the predicted SRC matches the observed SRC in a least squares sense. The initial loads for the chosen $T_{e}$ are used to find the wavenumber-dependent ratio between the spectra of initial subsurface and surface loads, $f(k)$ (e.g., Forsyth, 1985; Kirby and Swain, 2008). Here we choose to follow McKenzie (2003) and represent the loading ratio $f$ (which is unbounded) as $F=f /(1+f)$, the subsurface load fraction, which is bounded.

We use Brent's method (Press et al., 1992) in the inversion to find the best-fitting predicted SRC, with the difference between observed and predicted SRCs weighted by the inverse of equivalent Fourier wavenumber (Kirby and Swain, 2006). This inversewavenumber method generally gives smoother $T_{e}$ maps, as it down-weights the noisy SRCs that sometimes occur at high wavenumbers. Errors on $T_{e}$ are given as $95 \%$ confidence limits on the best-fitting value. Unfortunately, load-deconvolution cannot give errors on $F$, nor can it utilise errors on the observed gravity or topography data. This latter shortcoming is mitigated perhaps by the inverse-wavenumber weighting we use in the inversion of the coherence.

Load deconvolution requires detailed information on the internal structure of the lithosphere. We follow Forsyth's (1985) original formulation of the predicted coherence 
method, assuming that all internal loading occurs at the crust-mantle interface. To define the lateral variation of the Moho relief, we use the global crustal thickness model obtained in this study (see Section 3). Table 1 shows the values of the crustal and mantle densities used in the SRC inversion, together with the values of other required constants.

The $T_{e}$ and $F$ values in each tile were then merged to provide seamless coverage over the planet, as described in Section 2.

\section{Table 1}

Symbols and values of constants

\begin{tabular}{lccc}
\hline \multicolumn{1}{c}{ Constant } & Symbol & Value & Units \\
\hline Young's modulus & $E$ & 100 & $\mathrm{GPa}$ \\
Poisson's ratio & $v$ & 0.25 & \\
Newtonian gravitational constant & $G$ & $6.67259 \times 10^{-11}$ & $\mathrm{~m}^{3} \mathrm{~kg}^{-1} \mathrm{~s}^{-2}$ \\
Gravity acceleration & $g$ & 8.87 & $\mathrm{~m} \mathrm{~s}^{-2}$ \\
Mean planetary radius & $R$ & 6052 & $\mathrm{~km}$ \\
Mean crustal thickness & $T_{c}$ & 25 & $\mathrm{~km}$ \\
Crust density & $\rho_{c}$ & 2900 & $\mathrm{~kg} \mathrm{~m}^{-3}$ \\
Mantle density & $\rho_{m}$ & 3300 & $\mathrm{~kg} \mathrm{~m}^{-3}$ \\
\hline
\end{tabular}

\section{Results of effective elastic thickness mapping}

\subsection{Description of the $T_{e}$ map}

The effective elastic thickness results are shown in Fig. 6a. $T_{e}$ values range between 14 (the minimum resolvable $T_{e}$ value; see Section 2) and $94 \mathrm{~km}$, although low to moderate values clearly dominate (Fig. 7a). The most noticeable feature on the $T_{e}$ map is the extensive low to moderate $T_{e}(<40 \mathrm{~km})$ region associated with Ishtar, western Aphrodite (Ovda Regio) and Lada terrae, Alpha, Bell, Tellus and Eistla regiones, and parts of Lavinia, Atalanta and Niobe planitiae. Otherwise, the Beta-Atla-Themis (BAT) region and the southern planitiae show more variable $T_{e}$ results, including very high values. In western Aphrodite Terra, Thetis Regio is characterized by a slightly higher 
$T_{e}$, and the Artemis region (following the terminology of Hansen, 2002) is also characterized by moderate $T_{e}$ values $(\sim 45 \mathrm{~km})$. These $T_{e}$ values increase toward Nsomeka Planitia, which along with Aino and Helen planitiae show a complex pattern, with patches and regions of high to low $T_{e}$. In the northern hemisphere of Venus, Guinevere Planitia also shows this pattern. On the other hand, the large volcanic rises show a complex signature. Atla and Themis regiones seem to be uniformly strong $\left(T_{e}>\right.$ $50 \mathrm{~km}$ ), Dione Regio is characterized in large part by low $T_{e}$ values $(<30 \mathrm{~km})$, and Beta, Imdr and Laufey regiones exhibit a more complex $T_{e}$ pattern. Within the BAT region, our results show low to high $T_{e}$ values associated with Phoebe Regio. Our results also show a zone of high $T_{e}$ associated with Dali Chasma and the Atahensik Corona region. Otherwise, the graben-fissure systems in Hecate Chasma and Ulfrun Regio areas, as well as Beta Regio and Devana Chasma areas, are also associated with a wide range of $T_{e}$ values.

Fig. 6b shows best fitting $F$ values at the SRC transition wavenumber corresponding to the $T_{e}$ results in Fig. 6a (see also the histogram in Fig 7b). Interestingly, surface loads dominate a large part of the BAT region (associated with moderate to high $T_{e}$ values; see Fig. 6), with some exceptions as south of Atla Regio or surrounding of Phoebe Regio. Themis, Laufey, and western and central Eistla regiones are also dominated by surface loads. Nevertheless, Tellus, Alpha, Dione, Imdr and eastern Eistla regiones exhibit a more complex signature, characterized by moderate $F$ values. On the other hand, our load ratio estimates indicate that subsurface loading dominates (at least slightly) on Aphrodite Terra (associated with low to moderate $T_{e}$ values). Ishtar Terra is also dominated by subsurface loads; nonetheless, Lakshmi Planum is associated with a small load ratio, indicating that surface loads dominate. Lada Terra exhibits a more complex signature, with a broad range of $F$ values. Finally, 
planitiae and lowlands regions in both hemispheres show a wide range of $F$ values.

\subsection{Caveats and limitations}

As mentioned in Section 4, the load deconvolution and inversion methods allow for the estimation of errors on $T_{e}$ via $95 \%$ confidence limits on its best-fitting value. Fig 8a shows the spatial distribution of $T_{e}$ errors, and it can be seen that they are uniformly low ( $<8 \mathrm{~km})$ and show very little correlation with the absolute $T_{e}$ values in Fig 6a. This is unusual in $T_{e}$-mapping by spectral methods where $T_{e}$ error most often increases with $T_{e}$ value (e.g., Kirby, 2014). Earth elastic thicknesses, however, exhibit much higher values $(>100 \mathrm{~km})$ over larger areas, especially in cratons, and Fig. 7a shows that approximately $94 \%$ of the Venusian $T_{e}$ is $<60 \mathrm{~km}$, a value considered middling on Earth's continents. The lack of correlation between Venusian $T_{e}$ and its uncertainty may be related to the smaller $T_{e}$ values compared to Earth.

Unfortunately the spectral method of $T_{e}$ estimation does not allow for data errors to be propagated through to $T_{e}$, or even coherence, so the error map in Fig 8a takes no account of these. On Earth's continents this does not present such an issue due to high data density from many independent sources. Of particular note are the large errors in the SHGJ180u harmonic coefficients of the gravity field beyond degrees 60-70. While one could band-limit the gravity and topography data (excluding coefficients beyond degree 60 for instance) and perform the $T_{e}$ estimation again, the results might not be instructive. Truncation at degree 60 gives a minimum wavelength in the data of approximately $630 \mathrm{~km}$, which, if taken as a flexural wavelength implies a minimum resolvable $T_{e}$ of $60 \mathrm{~km}$, using the formula in Section 2. Such a $T_{e}$ map would be highly artificial. However, our choice to include higher harmonic degrees in the inversion does imply that some caution is required in the interpretation of the results, due to errors in 
the data at such degrees. Also, note that the spherical harmonic coefficients were biased towards a global power law (i.e., a 'Kaula rule’; Wieczorek, 2007), affecting the lower range of $T_{e}$ values (Audet, 2014).

In addition, the tesseral harmonics $(l \neq m)$ have large errors due to the near-polar orbit of the Magellan spacecraft (Konopliv et al., 1999). This phenomenon will generate a directional bias in the gravity data, leading to artificially anisotropic coherencies at the corresponding harmonics (wavenumbers). We suggest, however, that the azimuthalaveraging performed by the fan wavelet will reduce this error, though we do not know by how much. The variance of the resulting isotropic coherency may also be larger, owing to these errors.

The load deconvolution and inversion methods used here cannot provide errors on the loading ratio, $f$, since this is not an inversion parameter. We can, however, plot the spatial variation of the chi-squared statistic minimised in the inversion, where

$$
\chi^{2}=\sum_{k}\left(\frac{\Gamma_{B, o, R}^{2}(k)-\Gamma_{B, p, R}^{2}(k)}{\varepsilon_{\Gamma_{B, o, R}^{2}}(k)}\right)^{2},
$$

(e.g., Press et al., 1992), where the summation is over wavenumber, $k, \Gamma_{B, o, R}^{2}$ is the observed Bouguer SRC, $\Gamma_{B, p, R}^{2}$ is the predicted Bouguer SRC, and $\varepsilon_{\Gamma_{B, 0, R}^{2}}$ are the errors on the observed Bouguer SRC. Such a map is shown in Fig 8b, and provides a measure of how well the observed and best-fitting predicted SRCs fit one another. It therefore contains qualitative information about both $T_{e}$ and $f$ (or $F$ ) errors, and shows regions where the model may be inappropriate and/or the data errors have been underestimated. Unfortunately the map is noticeably biased by the tile shape for two of the tiles (see Fig 2). In addition, we check the robustness of the inversion in Appendix A. Fig. A1 and 
Fig. A2 show the results of inverting wavelet squared-coherency profiles for the parameters $T_{e}$ and $F$ in various locations. We used the normalized imaginary component of the free-air coherency for identifying coherence-biasing noise when inverting the Bouguer coherence (SRC); large values near the transition from low to high Bouguer SRC indicate a $T_{e}$ estimate biased by gravitational noise (see e.g., Kirby and Swain, 2009 for details). We note that the Bouguer SRCs are greatly affected by gravitational noise in many cases, and may lead to the biased estimation of lithospheric parameters, especially near the poles. As mentioned above, the spatial resolution of the gravity and topography data varies dramatically with the position on the surface, and large errors in gravity data closer to the poles may affect the accuracy of the results obtained in these zones, which may therefore be biased by noise; however, we also note that much more work is required to explore the noise issue in detail.

We find, though, that there is not an obvious correlation between $T_{e}$ and $F$, shown in Fig 7c. Many studies on earth have found a spatial correlation between maps of $T_{e}$ and $F$ (e.g., Tassara et al, 2007; Kirby and Swain, 2008) that would produce an approximately straight line in plots such as Fig 7c. For our Venus results we see very little evidence of such correlation, with a wide distribution in $T_{e}-F$ space. The points are bounded quite strongly on the lower- $T_{e}$ side though, perhaps reflecting the correlation seen on Earth.

In summary, we acknowledge the limitations of our analysis due to data quality. We believe that any $T_{e}$-estimation method would be hampered by these limitations until better data acquired by future geophysical exploration of Venus are available.

\subsection{Comparison with previous results}

Our pattern of $T_{e}$ variations is consistent with previous studies. However, we found some important differences in the results, related to the different approach and 
parameters used in the analysis. Anderson and Smrekar (2006) estimated $T_{e}$ from a global mapping of the admittance using the spatio-spectral localization technique of Simons et al. (1997) and three end-member models of loading (top loading, bottom loading, or hot spot), fitting their results to specified classes of results. The authors found $T_{e}$ values varying between 0 and $100 \mathrm{~km}$, with $T_{e}<20 \mathrm{~km}$ for approximately half of the planet, while our results show a similar range but predominantly dominated by moderate $T_{e}$ values, peaking around $35-40 \mathrm{~km}$. We suggest that our approach is more rigorous due to (1) spectral biases in their method (Wieczorek and Simons, 2005), and (2) their fixing of $F$ prior to inversion.

Our results also show differences with the global $T_{e}$ and $F$ maps recently obtained by Audet (2014) for Venus. However, there are also differences between the methods in these two studies. (a) Audet (2014) used 5-degree mean gravity anomalies and topography; we used data on a $20 \mathrm{~km}$ grid with $T_{e}$ averaged onto a 1-degree grid. (b) Audet (2014) used the spherical wavelet transform on unprojected data; we use a planar version on projected data [though as Audet (2014) showed, this analysis method difference yields small $T_{e}$ differences]. (c) Audet (2014) used equations for the flexure of a thin elastic shell; we use those for a thin elastic plate. (d) Audet (2014) performed a joint inversion of the admittance and coherency with analytical expressions (the socalled 'uniform- $f$ ' method); we use load deconvolution with the SRC and retrieve a wavenumber-dependent $F$. While it is not possible to point to a 'better' $T_{e}$ result, the spherical approach is undoubtedly more rigorous than a planar approximation, while load-deconvolution is more realistic than uniform- $f$ inversion.

\section{Discussion}

The patterns of $T_{e}$ and $F$ variations show a high variability. This could suggest 
that Venus remains an active planet with complex geologic processes, as previously suggested by Anderson and Smrekar (2006). However, this might be true only taking into account the relatively young ages typical of the Venusian surface (e.g., Basilevsky and Head, 1998; Guest and Stofan, 1999; Ivanov and Head, 2011), because a very high range of $T_{e}$ values could be indicating a temporal trend. Indeed, the range of $T_{e}$ values obtained for Mars (for a compilation see Ruiz, 2014) is larger than for Venus, but it seems mostly to be a consequence of secular planetary evolution (e.g., McGovern et al., 2002), related to cooling and thickening of the lithosphere (Ruiz, 2014). This can be so because the observed $T_{e}$ values derive from the state of the lithosphere when the topography was formed (or, in the case of the $T_{e}$ calculated from spectral methods, when the relation between topography and gravity was established) (Watts, 2001). There is evidence that crustal plateaus are the oldest (or at least slightly older) terrains on Venus (e.g., Ivanov and Head, 2011), which would be consistent with a lower elastic thickness and near-isostatic compensation (see Fig. 6). This is consistent with their small gravity anomalies, low geoid-to-topography ratios (GTRs), and shallow apparent depths of compensation (ADCs); all indicating a thickened crust beneath them (e.g., Smrekar and Phillips, 1991; Kucinskas and Turcotte, 1994; Grimm, 1994; Simons et al., 1997; Anderson and Smrekar, 2006; James et al., 2013).

Fig. 9 shows an equatorial transect of our crustal thickness and effective elastic thickness models. Higher $T_{e}$ values generally occur in areas of normal crustal thickness $(\approx 20-25 \mathrm{~km}$ ), which is consistent with the lowland topography being formed when the lithosphere of Venus was cooler than at the time of the formation of the crustal plateaus. In general, most $T_{e}$ estimates are higher than the crustal thickness, suggesting a significant contribution of the upper mantle to the strength of the lithosphere in many areas. It must be recalled that the effective elastic thickness does not, in general, 
represent an actual layer, rather it is a measurement of lithospheric strength which integrates contributions from mechanically strong portions of the crust and mantle (see Watts and Burov, 2003). Mantle rocks are stronger than crustal rocks, but being under higher temperatures, their strength is reduced. For a sufficiently high heat flow the upper mantle does not contribute to $T_{e}$, and the lithosphere is thin and restricted to the crust; conversely, if the heat flow is sufficiently low, the upper mantle is cold and strong, and contributes to the strength of the lithosphere, and hence to the effective elastic thickness, which is therefore higher. Thus at least part of the regional variations of $T_{e}$ could be due to differences in the cooling history of the lithosphere in these regions, although deep geodynamic processes with little surface manifestation could also be operating (see Anderson and Smrekar, 2006). In this sense, mantle processes could produce a pattern of low to moderate $T_{e}$ associated with a large region enclosing very different geological features, such as crustal plateaus and planitiae, with different relative surface ages.

The large volcanic rises show a complex $T_{e}$ signature, which, along with their large ADCs and GTRs (e.g., Kucinskas and Turcotte, 1994; Smrekar, 1994; Moore and Schubert, 1997; James et al., 2013), suggests that the topography may be supported through a combination of several mechanisms (see also Kucinskas and Turcotte, 1994; Moore and Schubert, 1997; Vezolainen et al., 2004; Pauer et al., 2006). James et al. (2013) recently found that the topography of certain regions, such as Atla and Eistla regiones, is mainly supported by dynamic loading, or in the case of Thetis Regio, by contributions from both crustal thickening and dynamic support from the mantle.

We have examined the effective elastic thickness in relation to the crater density (Fig. 10) by using a global database of impact craters on its surface (Schaber et al., 1998). The impact crater population on Venus, which gives a mean surface age of 300- 
1000 Myr (McKinnon et al., 1997), shows a nearly uniform spatial distribution (Schaber et al., 1992; Phillips et al., 1992; Strom et al., 1994). In Fig. 10 we plot the crater density (points) obtained with sampling windows of $10^{6} \mathrm{~km}^{2}$ against the mean value of $T_{e}$ in each window. We found that most of the craters are located in regions with low or moderate $T_{e}$, although this possible correlation could be biased by the distribution of $T_{e}$, clearly dominated by that range of low to moderate values. Alternatively, we also plot a second analysis of the crater density (superposed white squares and black line) calculated by counting the number of craters for $T_{e}$ intervals of $10 \mathrm{~km}$ providing the crater density of each interval (in $10^{6} \mathrm{~km}^{2}$ ), to avoid the effect of windowing. This analysis shows a higher (at least relatively) crater density associated with moderate to high $T_{e}$ values. Although the high $T_{e}$ intervals show a comparatively low number of craters, the corresponding areas are so small that the crater density is slightly increased; therefore these results may be biased upward. This implies that there is no evidence of a clear correlation between $T_{e}$ and the crater density, consistent with the previous observations of Barnett et al. (2002).

The spatial and temporal distribution of surface volcanism (as expressed by Venusian volcanoes and coronae) also might provide essential information on the geologic history and geodynamic evolution of Venus. We compare our $T_{e}$ and $F$ frequency estimates (Fig. 11a) with volcanoes (from the USGS Venus Volcano Catalog; Schaber et al., 1998) and coronae (Stofan et al., 2001) frequency distributions (Fig. 11b,c). We find that there is not a significant correlation between lithospheric parameters and the frequency distribution of volcanoes and coronae, whose patterns closely mimic the distribution of $T_{e}$ and $F$ on the surface. Although we do not show it here for brevity, there are no significant differences in lithospheric properties between Type 1 and Type 2 coronae (see Coronae Type definition by Stofan et al., 2001), 
confirming the previous observations of Smrekar and Stofan (2003). The only noticeable difference is a slight trend toward smaller $F$ values, and maybe toward higher $T_{e}$ values, in the frequency distribution of coronae. We note that these patterns may be largely controlled by the spatial distribution of the volcanic features on the planetary surface, where the BAT region is characterized by a concentration of volcanic activity (see e.g., Crumpler et al., 1997). Indeed, surface loads dominate a large part of this region, associated with a wide range of $T_{e}$ values; including higher values (see Fig. 6). However, it is important to keep in mind that $T_{e}$ and $F$ values in Fig. 11b,c derive from the global mapping, not from estimates for each individual feature, especially taking into account the high number of coronae (more than 50\%) with a smaller diameter than the minimum flexural wavelength used in our analysis (211 km; see Section 2). Thus, these results should be interpreted in a general sense.

\section{Conclusions}

In this paper we investigate the lithospheric strength of Venus by calculating its effective elastic thickness from the analysis of gravity and topography. We first present a crustal thickness model, in which the majority of Venusian crust is $20-25$ km thick, with thicker crust under the highlands. This suggests that most of the Venusian crust was emplaced under similar conditions, and different to those generating the crustal plateaus.

We find effective elastic thickness values up to $\approx 95 \mathrm{~km}$ for Venus, but they are mostly of low to moderate value. $T_{e}$ variations and patterns could represent regional variations in the cooling history of the lithosphere and/or mantle processes with limited surface manifestation. The crustal plateaus are near-isostatically compensated, consistent with a thin elastic lithosphere, showing a thickened crust beneath them, 
whereas the lowlands exhibit higher $T_{e}$ values, maybe indicating a cooler lithosphere than that when the Venusian highlands were emplaced. The large volcanic rises show a complex signature, with a broad range of $T_{e}$ and $F$ values. Our results also reveal a significant contribution of the upper mantle to the strength of the lithosphere.

We find that there is not an obvious correlation between $T_{e}$ and crater density on the Venusian surface, as well as between the lithospheric parameters and the distribution of volcanoes and coronae.

The effective elastic thickness is a very useful indicator of the strength and mechanical behaviour of the lithosphere. Recent advances in mapping of $T_{e}$ represent a great opportunity, as well as a great challenge, for future work. Limitations due to resolution of the available data emphasize the importance of future missions to map out the gravity and topography of Venus with sufficiently high resolution in order to produce regional lithospheric models and solve key gaps in the understanding of the lithospheric structure and evolution of Venus.

\section{Acknowledgements}

We thank Pascal Audet and an anonymous reviewer for their useful reviews that significantly improved this manuscript. We also thank USGS for the online distribution of the databases used in this study, and Mark A. Wieczorek and Matthias Meschede for making their SHTOOLS software package available (Wieczorek and Meschede, 2015; available at https://github.com/SHTOOLS/SHTOOLS/releases), which was used to process the Magellan data products obtained from the PDS Geosciences Node (http://pds-geosciences.wustl.edu). Also, we would like to thank Valle López for her encouragements and help during the realization of this work. All figures were plotted using GMT (Wessel et al., 2013; available at http://gmt.soest.hawaii.edu/home). A.J.-D. 
work was supported by a grant of the Complutense University of Madrid. J.R. work was supported by a contract Ramón y Cajal co-financed from the the Spanish Ministry of Economy and Competitiveness and the European Social Fund. This work was supported by the project CGL2011-23857 from the Spanish Ministry of Economy and Competitiveness.

\section{Appendix A. One-dimensional profiles of the squared-coherency}

Fig. A1 and Fig. A2 show the results of inverting wavelet squared-coherency profiles $\left(\left|\mathbf{k}_{0}\right|=5.336\right)$ for the parameters $T_{e}$ and $F$ in several locations, to check the robustness of the inversion. Rather than computing the coherency at each of the $20 \times 20$ km grid nodes (see Section 2), we spatially averaged the autospectra and cross-spectra over $25 \times 25$ grid nodes, giving a $500 \times 500 \mathrm{~km}$ spatially averaged coherency. Inversions for $T_{e}$ and $F$ were performed on the spatially averaged observed coherencies, over wavelengths $>211 \mathrm{~km}$; more details can be found in the main text. The thin red lines show the normalized imaginary component of the free-air coherency. Large values near the transition from low to high Bouguer SRC indicate a $T_{e}$ estimate biased by gravitational noise. We also report estimates of the best fitting $T_{e}$ and $F$, as well as the value of the $T_{e}$ error and chi-squared misfit at all locations.

\section{References}

Anderson, F.S., Smrekar, S.E., 2006. Global mapping of crustal and lithospheric thickness on Venus. J. Geophys. Res. 111, E08006.

Audet, P., 2011. Directional wavelet analysis on the sphere: application to gravity and topography of the terrestrial planets. J. Geophys. Res. 116, E01003.

Audet, P., 2014. Toward mapping the effective elastic thickness of planetary 
lithospheres from a spherical wavelet analysis of gravity and topography. Phys. Earth Planet. Inter. 226, 48-82.

Audet, P., Bürgmann, R., 2011. Dominant role of tectonic inheritance in supercontinent cycles. Nat. Geosci. 4, 184-187.

Baratoux, D., Samuel, H., Michaut, C., Toplis, M.J., Monnereau, M., Wieczorek, M., Garcia, R., Kurita, K., 2014. Petrological constraints on the density of the Martian crust. J. Geophys. Res. Planets, 119, 1707-1727.

Barnett, D.N., Nimmo, F., McKenzie, C., 2000. Elastic thickness estimates for Venus using line of sight accelerations from Magellan Cycle 5. Icarus 146, 404-419.

Barnett, D.N., Nimmo, F., McKenzie, D., 2002. Flexure of Venusian lithosphere measured from residual topography and gravity. J. Geophys. Res. 107 (E2).

Basilevsky, A.T., Head, J.W., 1998. The geologic history of Venus: A stratigraphic view. J. Geophys. Res. 103, 8531- 8544.

Cheung, K.K., King, S.D., 2014. Geophysical evidence supports migration of Tharsis volcanism on Mars. J. Geophys. Res. 119, 1078-1085.

Crumpler, L.S., Aubele, J.C., Senske, D.A., Keddie, S.T., Magee, K.P., Head, J.W., 1997. Volcanoes and centers of volcanism on Venus, in: Bougher, W., Hunten, D.M., Phillips, R.J. (Eds.), Venus II. Univ. of Arizona Press, Tucson, pp. 697-756.

Forsyth, D.W., 1985. Subsurface loading estimates of the flexural rigidity of continental lithosphere. J. Geophys. Res. 90, 12,623-12,632.

Garvin, J.B., Glaze, L.S., Campbell, B., Ford, P., Lemoine, F., Neumann, G., Phillips, R., Raney, K., 2009. Venus: Constraining Crustal Evolution from Orbit Via HighResolution Geophysical and Geological Reconnaissance. Venus White Paper for Planetary Sciences Decadal Survey, Inner-Planets Panel, 8 pp.

Ghail, R., Wilson, C., Galand, M., Hall, D., Cochrane, C., Mason, P., Helbert, J., 
MontMessin, F., Limaye, S., Patel, M., Bowles, N., Stam, D., Wahlund, J.-E., Rocca, F., Waltham, D., Mather, T., Biggs, J., Genge, M., Paillou, P., Mitchell, K., Wilson, L., Singh, U., 2012. EnVision: taking the pulse of our twin planet. Exp Astron 33, 337-363.

Ghent, E.D, Dipple, G.M., Russell, J.K., 2004. Thermodynamic models for eclogitic mantle lithosphere. Earth Planet. Sci. Lett. 218, 451-462.

Grimm, R.E., 1994. The deep structure of Venusian plateau highlands. Icarus 112, 89103.

Grimm, R.E., Hess, P.C., 1997. The crust of Venus, in: Bougher, W., Hunten, D.M., Phillips, R.J. (Eds.), Venus II. Univ. of Arizona Press, Tucson, pp. 1205-1244.

Guest, J.E., Stofan, E.R., 1999. A new view of the stratigraphic history of Venus. Icarus 139, 55-66.

Hansen, V.L., 2002. Artemis; surface expression of a deep mantle plume on Venus. Geological Society of America Bulletin 114, 839-848.

Hoogenboom, T., Houseman, G., Martin, P., 2005. Elastic thickness estimates for coronae associated with chasmata on Venus. J. Geophys. Res. 110, E09003.

Hoogenboom, T., Smrekar, S.E., Anderson, F.S., Houseman, G., 2004. Admittance survey of type 1 coronae on Venus. J. Geophys. Res. 109, E03002.

Ivanov, M.A., Head, J.W., 2011. Global geological map of Venus. Planetary and Space Science 59, 1559-1600.

James, P.B., Zuber, M.T., Phillips, R.J., 2013. Crustal thickness and support of topography on Venus. J. Geophys. Res. 118, 859-875.

Johnson, C.L., Sandwell, D.T., 1994. Lithospheric flexure on Venus. Geophys. J. Int. $119,627-647$.

Jull, M.G., Arkani-Hamed, J., 1995. The implications of basalt in the formation and 
evolution of mountains on Venus. Phys. Earth Planet. Inter. 89, 163-175.

Kirby, J.F., Swain, C.J., 2006. Mapping the mechanical anisotropy of the lithosphere using a 2D wavelet coherence, and its application to Australia. Physics of the Earth and Planetary Interiors 158(2-4), 122-138.

Kirby, J.F., Swain, C.J., 2008. An accuracy assessment of the fanwavelet coherence method for elastic thickness estimation. Geochemistry, Geophysics, Geosystems 9 (3), Q03022. (Correction. 2008. Geochemistry, Geophysics, Geosystems 9(5), Q05021).

Kirby, J.F., Swain, C.J., 2009. A reassessment of spectral Te estimation in continental interiors: the case of North America. Journal of Geophysical Research 114, B08401.

Kirby, J.F., Swain, C.J., 2011. Improving the spatial resolution of effective elastic thickness estimation with the fan wavelet transform. Computers \& Geosciences $37,1345-1354$.

Kirby, J.F., Swain, C.J., 2013. Power spectral estimates using two-dimensional Morletfan wavelets with emphasis on the long wavelengths: jackknife errors, bandwidth resolution and orthogonality properties. Geophys. J. Int. 194, 78-99.

Kirby, J.F., 2014. Estimation of the effective elastic thickness of the lithosphere using inverse spectral methods: The state of the art. Tectonophysics 631, 87-116.

Konopliv, A.S., Banerdt, W.B., Sjogren, W.L., 1999. Venus gravity: 180th degree and order model. Icarus 139, 3-18.

Konopliv, A.S., Sjogren, W.L., 1994. Venus spherical harmonic gravity model to degree and order 60. Icarus 112, 42-54.

Kucinskas, A.B., Turcotte, D.L., 1994. Isostatic compensation of equatorial highlands on Venus. Icarus 112, 104-116. 
McGovern, P.J., Solomon, S.C., Smith, D.F., Zuber, M.T., Simons, M., Wieczorek, M.A., Phillips, R.J., Neumann, G.A., Aharonson, O., Head J.W., 2002. Localized gravity/topography admittance and correlation spectra on Mars: Implications for regional and global evolution. J. Geophys. Res. 107, 5136.

McKenzie, D., 2003. Estimating Te in the presence of internal loads. Journal of Geophysical Research 108 (B9), 2438.

McKenzie, D., Nimmo, F., 1997. Elastic thickness estimates for Venus from line of sight accelerations. Icarus 130, 198-216.

McKenzie, D.P., Fairhead, J.D., 1997. Estimates of the effective elastic thickness of the continental lithosphere from Bouguer and free air gravity anomalies. J. Geophys. Res., 102(B12), 27 523-27 552.

McKinnon, W.B., Zahnle, K., Ivanov, B.A., Melosh, H.J., 1997. Cratering on Venus: modeling and observations, in: Bougher, W., Hunten, D.M., Phillips, R.J. (Eds.), Venus II. Univ. of Arizona Press, Tucson, pp. 969-1014.

Moore, W.B., Schubert, G., 1997. Venusian crustal and lithospheric properties from nonlinear regressions of highland geoid and topopgraphy. Icarus 128, 415-428.

Namiki, N., Solomon S.C., 1993. The gabbro-eclogite phase transition and the elevation of mountain belts on Venus. J. Geophys. Res. 98, 15,025-15,031.

Neumann, G.A., Zuber, M.T., Wieczorek, M.A., McGovern, P.J., Lemoine, F.G., Smith, D.E., 2004. Crustal structure of Mars from gravity and topography. J. Geophys. Res. 109, E08002.

Pauer, M., Fleming, K., Čadek, O., 2006. Modeling the dynamic component of the geoid and topography of Venus. J. Geophys. Res. 111, E11012.

Phillips, R.J., 1994. Estimating lithospheric properties at Atla Regio. Icarus 112, 147170. 
Phillips, R.J., Johnson, C.L., Mackwell, S.J., Morgan, P., Sandwell, D.T., Zuber, M.T., 1997. Lithospheric mechanics and dynamics of Venus, in: Bougher, W., Hunten, D.M., Phillips, R.J. (Eds.), Venus II. Univ. of Arizona Press, Tucson, pp. 11631204.

Phillips, R.J., Raubertas, R.F., Arvidson, R.E., Sarkar, I.C., Herrick, R.R., Izenberg, N., Grimm, R.E., 1992. Impact craters and Venus resurfacing history. J. Geophys. Res. 97, 15923-15948.

Press, W.H., Teukolsky, S.A., Vetterling, W.T., Flannery, B.P., 1992. Numerical Recipes in Fortran 77, $2^{\text {nd }}$ Ed., Cambridge University Press, Cambridge.

Rappaport, N.J., Konopliv, A.S., Kucinskas, A.B., 1999. An improved 360 degree and order model of Venus topography. Icarus 139, 19-31.

Ruiz, J., 2014. The early heat loss evolution of Mars and their implications for internal and environmental history. Sci. Rep. 4, 4338.

Ruiz, J., McGovern, P.J., Jiménez-Díaz, A., López, V., Williams, J.P., Hahn, B.C., Tejero, R., 2011. The thermal evolution of Mars as constrained by paleo-heat flows. Icarus 215, 508-517.

Schaber, G.G., Kirk, R.L., Strom, R.G., 1998. Data base of impact craters on Venus based on analysis of Magellan radar images and altimetry data. U.S. Geol. Surv. Open File Rep. 98-104.

Schaber, G.G., Strom, G.H., Moore, H.J., Soderblom, L.A., Kirk, R.L., Chadwick, D.J., Dawson, D.D., Gaddis, L.R., Boyce, J.M., Russell, J., 1992. Geology and distribution of impact craters on Venus: what are they telling us? J. Geophys. Res. 97 (E8), 13257-13301.

Simons M, Hager, B.H., Solomon, S.C., 1994. Global variations in the geoid/topography admittance of Venus. Science 264, 798-803. 
Simons, M., Solomon, S.C., Hager, B.H., 1997. Localization of gravity and topography: constraints on the tectonics and mantle dynamics of Venus. Geophys. J. Int. 131, 24-44.

Smith, W.H.F., Wessel, P., 1990. Gridding with continuous curvature splines in tension. Geophysics 55, 293-305.

Smrekar, S.E., 1994. Evidence for active hotspots on Venus from analysis of Magellan gravity data. Icarus 112, 2-26.

Smrekar, S.E., Phillips, R.J., 1991. Venusian highlands: Geoid to topography ratios and their implications. Earth Planet. Sci. Lett. 107, 582-597.

Smrekar, S.E., Stofan, E.R., 1999. Origin of corona-dominated topographic rises on Venus. Icarus 139, 100-115.

Smrekar, S.E., Stofan, E.R., 2003. Effects of lithospheric properties on the formation of Type 2 coronae on Venus. J. Geophys. Res. 108 (E8), 5091.

Smrekar, S.E., Stofan, E.R., Kiefer, W.S., 1997. Large volcanic rises on Venus, in: Bougher, W., Hunten, D.M., Phillips, R.J. (Eds.), Venus II. Univ. of Arizona Press, Tucson, pp. 845-878.

Smrekar, S.E., Stofan, E.R., Mueller, N., Treiman, A., Elkins-Tanton, L., Helbert, J., Piccioni, G., Drossart, P., 2010. Recent Hotspot Volcanism on Venus from VIRTIS Emissivity Data. Science 328, 605-608.

Solomon, S.C., Head, J.W., 1982. Mechanisms for lithospheric heat transport on Venus: Implications for tectonic style and volcanism. J. Geophys. Res. 87, 9,236-9,246.

Solomon, S.C., Smrekar, S.E., Bindschadler, D.L., Grimm, R.E., Kaula, W.M., McGill, G.E., Phillips, R.J., Saunders, R.S., Schubert, G., Squyres, S.W., and Stofan, E.R., 1992, Venus tectonics: An overview of Magellan observations. J. Geophys. Res. 97, 13,199-13,255. 
Sotin, C., Davaille, A., Lenardic, A., Smrekar, S.E., 2014. Venus’ interior structure and dynamics. EPSC Abstracts, Vol. 9, EPSC2014-711.

Stofan, E.R., Hamilton, V.E., Janes, D.M., Smrekar, S.E., 1997. Coronae on Venus: Morphology and Origin, in: Bougher, W., Hunten, D.M., Phillips, R.J. (Eds.), Venus II. Univ. of Arizona Press, Tucson, pp. 931-965.

Stofan, E.R., Smrekar, S.E., Tapper, S.W., Guest, J.E., Grindrod, P.M., 2001. Preliminary analysis of an expanded corona database for Venus. Geophys. Res. Lett. 28, 4267-4270.

Strom, R.G., Schaber, G.G., Dawson, D.D., 1994. The global resurfacing of Venus. J. Geophys. Res. 99 (E5), 10899-10926.

Swain, C.J., Kirby, J.F., 2003. The effect of 'noise' on estimates of the elastic thickness of the continental lithosphere by the coherence method, Geophys. Res. Lett. 30(11), 1574, doi:10.1029/2003GL017070.

Swain, C.J., Kirby, J.F., 2006. An effective elastic thickness map of Australia from wavelet transforms of gravity and topography using Forsyth’s method. Geophys. Res. Lett. VOL. 33, L02314, doi:10.1029/2005GL025090.

Tassara, A., Swain, C.J., Hackney, R.I., Kirby, J.F., 2007. Elastic thickness structure of South America estimated using wavelets and satellite-derived gravity data. Earth and Planetary Science Letters 253, 17-36.

VEXAG, 2014. Goals, Objectives, and Investigations for Venus Exploration 2014, Venus Exploration Analysis Group (VEXAG), [http://www.lpi.usra.edu/vexag], $21 \mathrm{pp}$.

Vezolainen, A.V., Solomatov, V.S., Basilevsky, A.T., Head, J.W., 2004. Uplift of Beta Regio: Three-dimensional models. J. Geophys. Res. 109, E08007.

Watts, A.B., 2001. Isostasy and Flexure of the Lithosphere. Cambridge University 
Press. 472 pp.

Watts, A.B., Burov, E.B., 2003. Lithospheric strength and its relation to the elastic and seismogenetic layer thickness. Earth Planet. Sci. Lett. 213, 113-131.

Watts, A.B., Zhong, S.J., Hunter, J., 2013. Lithosphere behaviour on seismic through geologic time-scales. Annual Reviews Earth \& Planetary Sciences 41, 443-468.

Wessel, P., Smith, W.H.F., Scharroo, R., Luis, J.F., Wobbe, F., 2013. Generic Mapping Tools: Improved version released, EOS Trans. AGU, 94, 409-410.

Wieczorek, M.A., 2007. Gravity and topography of the terrestrial planets, Treatise on Geophysics, Vol. 10, 165-206.

Wieczorek, M.A., Meschede, M., 2015. SHTOOLS - Tools for working with spherical harmonics (v3.0), ZENODO, doi:10.5281/zenodo.15967.

Wieczorek, M.A., Phillips, R.J., 1998. Potential anomalies on a sphere: applications to the thickness of the lunar crust. J. Geophys. Res. 103, 1715-1724.

Wieczorek, M.A., Simons, F.J., 2005. Localized spectral analysis on the sphere. Geophys. J. Int. 162, 655-675.

Zuber, M.T., 1987. Constraints on the lithospheric structure of Venus from mechanical models and tectonic surface features. J. Geophys. Res. 92, E541-E551.

Zuber, M.T., Solomon, S.C., Phillips, R.J., Smith, D.E., Tyler, G.L., Aharonson, O., Balmino, G., Banerdt, W.B., Head, J.W., Lemoine, F.G., 2000. Internal structure and early thermal evolution of Mars from Mars Global Surveyor topography and gravity. Science 287, 1788-1793. 

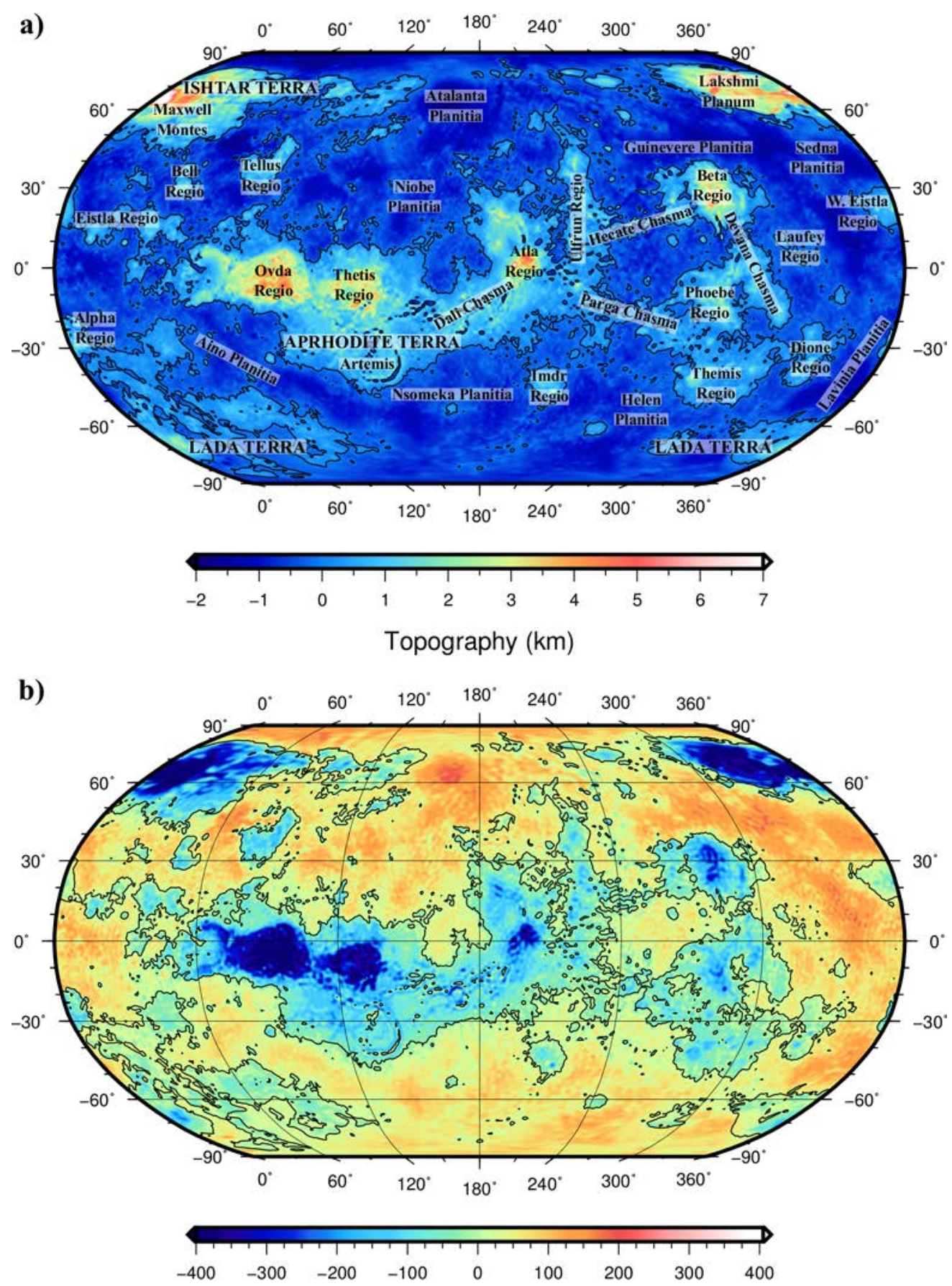

Bouguer anomaly (mGal)

Figure 1. (a) Topography and (b) Bouguer gravity anomaly of Venus derived from the spherical harmonic models SHTJV360u (Rappaport et al., 1999) and SHGJ180u (Konopliv et al., 1999), respectively, to degree and order 180. The map projection is Robinson with east-positive longitude convention and centred on $180^{\circ}$ longitude. Black contour is the zero topography contour. 


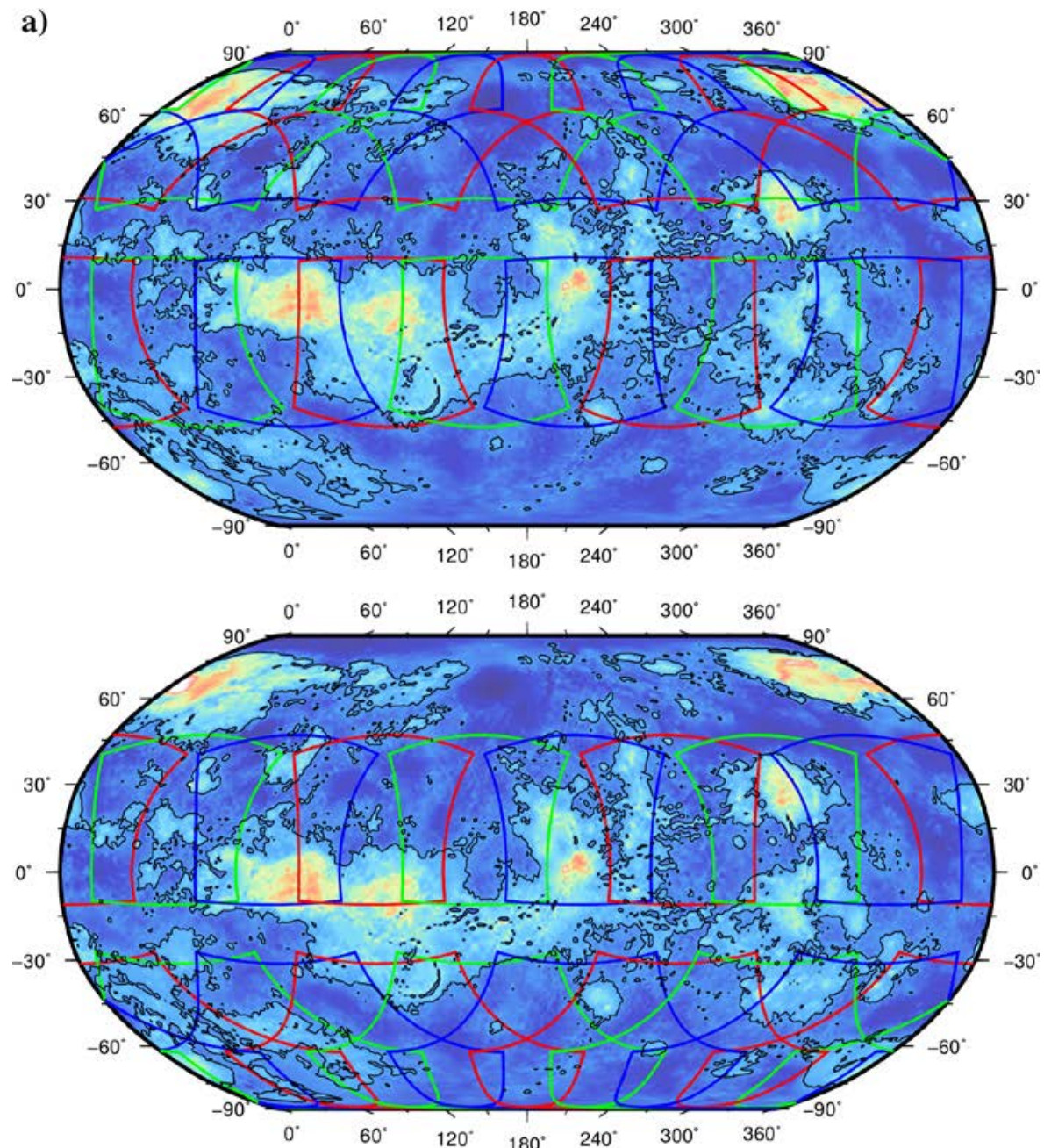

b)

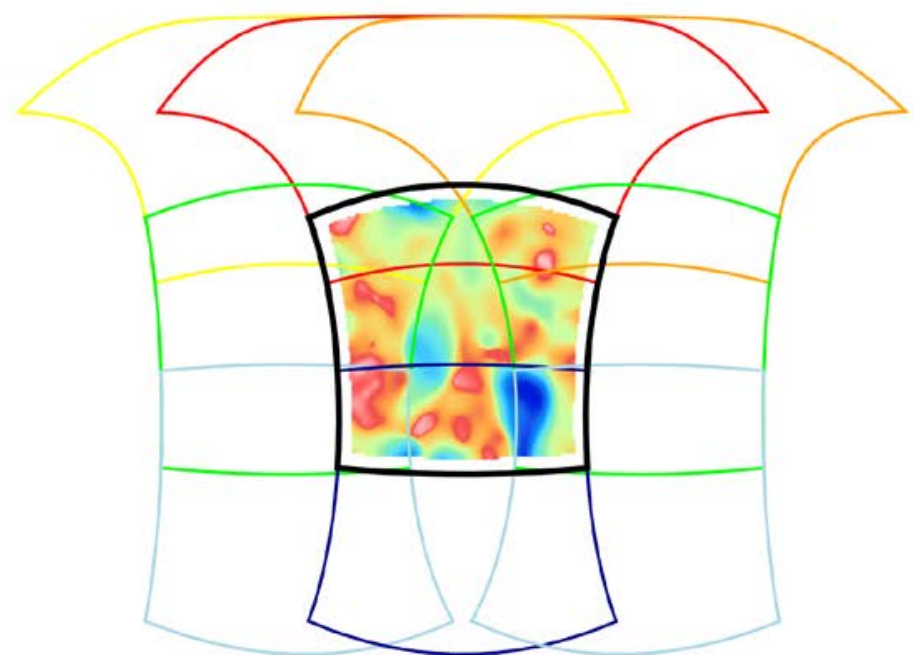

Figure 2. (a) The surface of Venus divided into 36 overlapping tiles (shown in two different maps - top and bottom - for the sake of figure clarity), from north to south and west to east. We projected the gravity and topography in each of them to a Cartesian frame using an oblique Mercator map projection, providing a global coverage. Each tile had dimensions of $6000 \mathrm{~km}$ (easting) x $6000 \mathrm{~km}$ (northing), and a grid spacing of $20 \mathrm{~km}$ in both directions. (b) Example of a tile (black thick line) with the ten percent of each side length ignored to mitigate possible remnant edge effects near the grid boundaries of the $T_{e}$ results, showing its overlap with the surrounding tiles. 

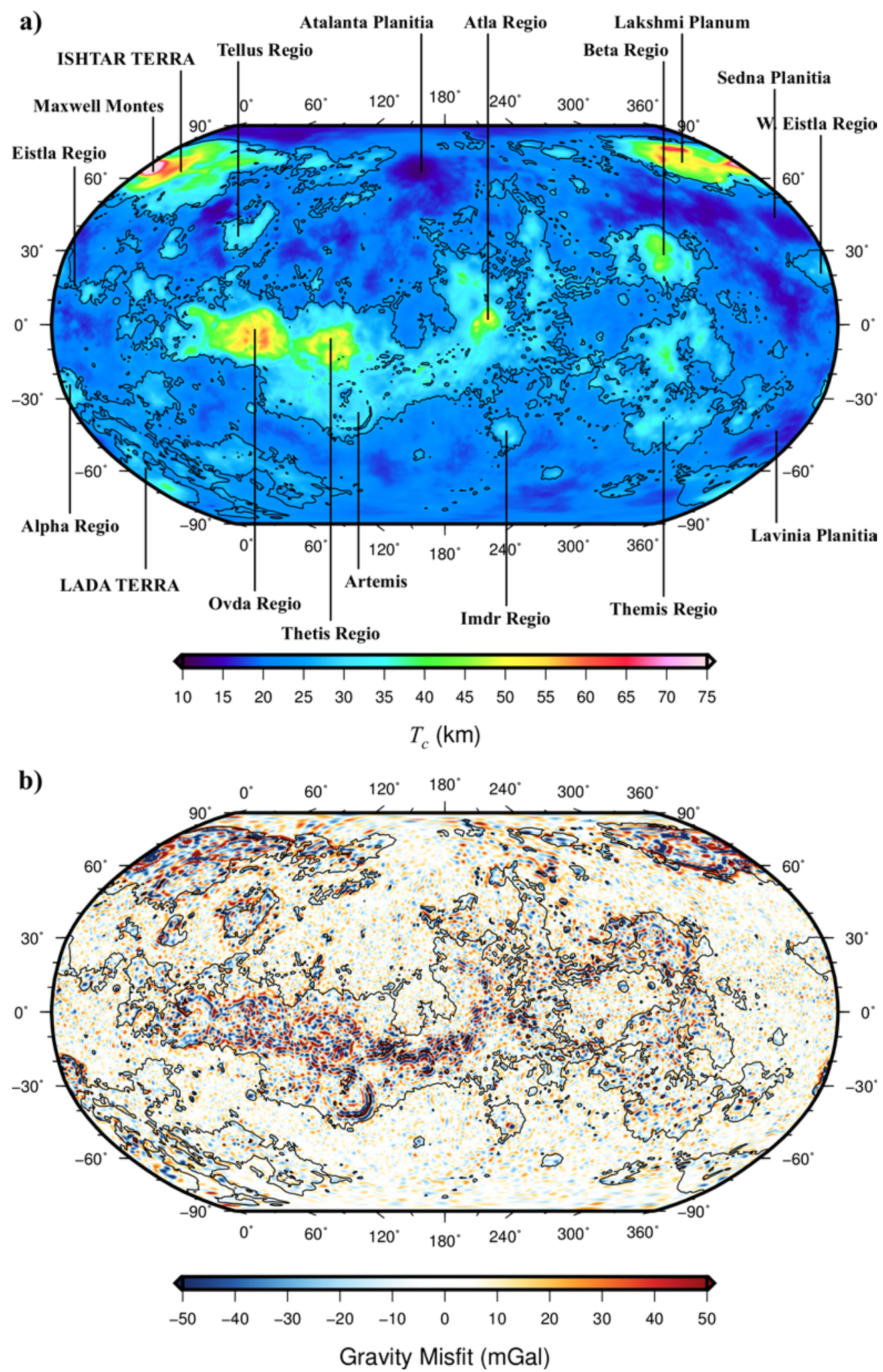

Figure 3. (a) Crustal thickness model for Venus assuming a mean crustal thickness of $25 \mathrm{~km}$, and crust and mantle densities of, respectively, 2900 and $3300 \mathrm{~kg} \mathrm{~m}^{-3}$. (b) Gravity misfit (the difference between observed and calculated gravity), derived from the crustal thickness modelling at spherical harmonic degree and order 180, corresponding to the results in (a) and Fig. 4. Black contour is the zero topography contour. 
a)

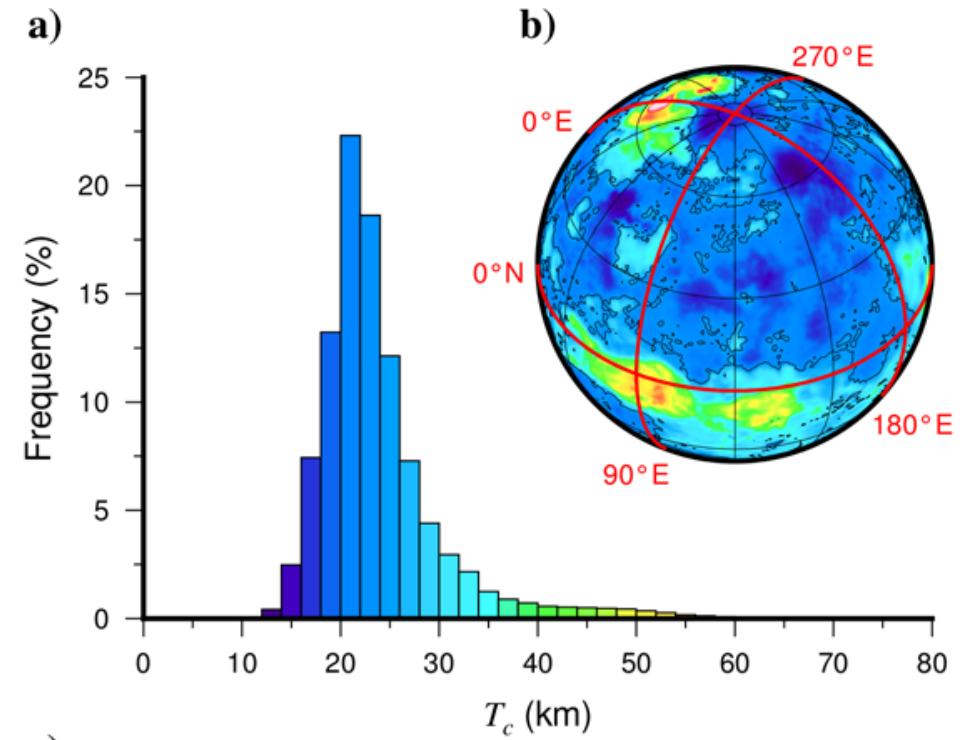

c)
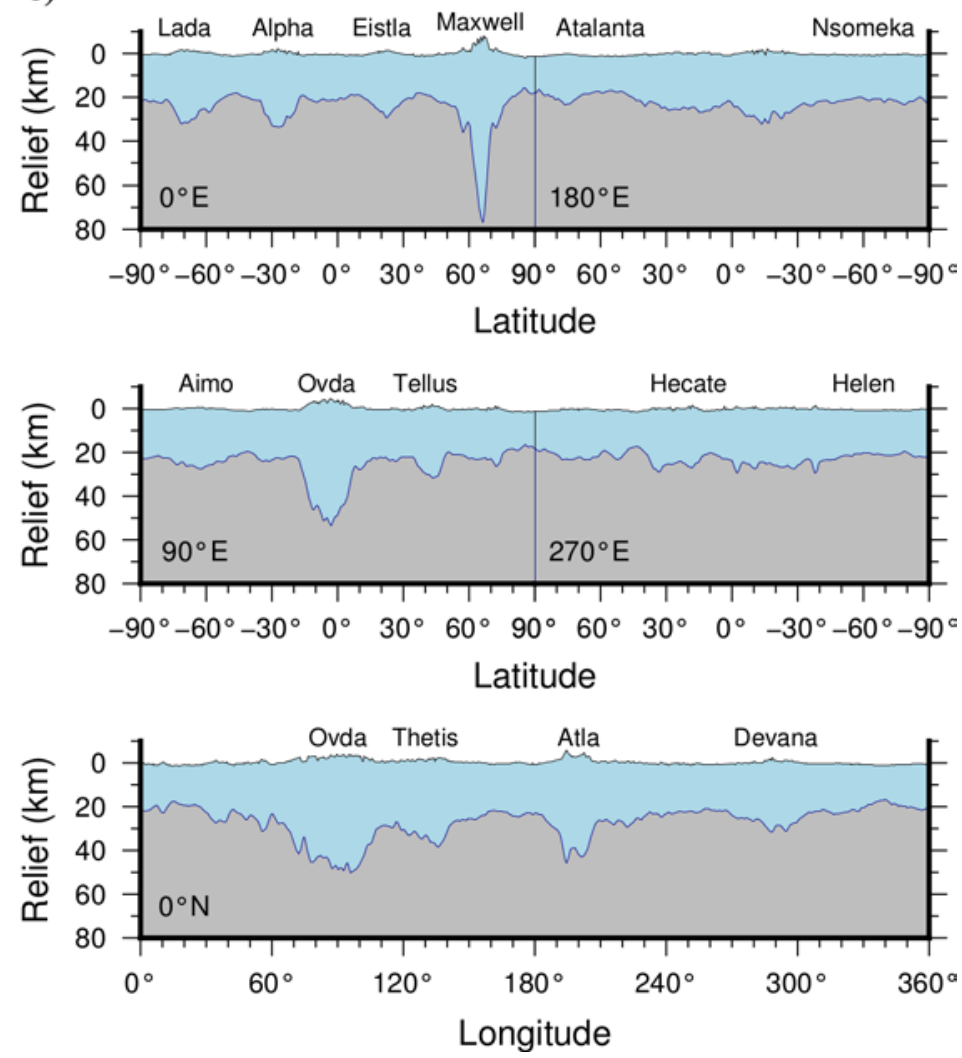

Figure 4. (a) Histogram of crustal thickness. (b) Crustal thickness model in an orthographic projection centred on $120^{\circ}$ longitude and $40^{\circ}$ latitude. The red lines correspond to the crustal structure profiles shown in (c). (c) Pole-to-pole longitudinal transects of the crustal structure, as well as an equatorial transect, where light blue corresponds to crust and gray corresponds to mantle. 


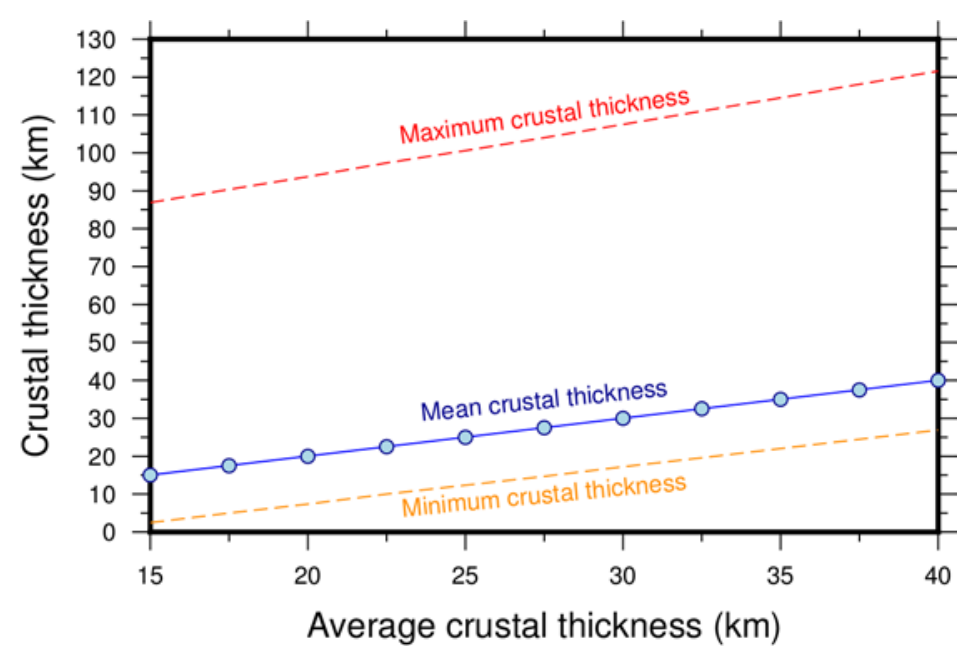

Figure 5. Minimum and maximum crustal thickness as a function of the average crustal thickness. For each crustal thickness inversion, the density contrast between the mantle and crust was constrained to be $400 \mathrm{~kg} \mathrm{~m}^{-3}$. 

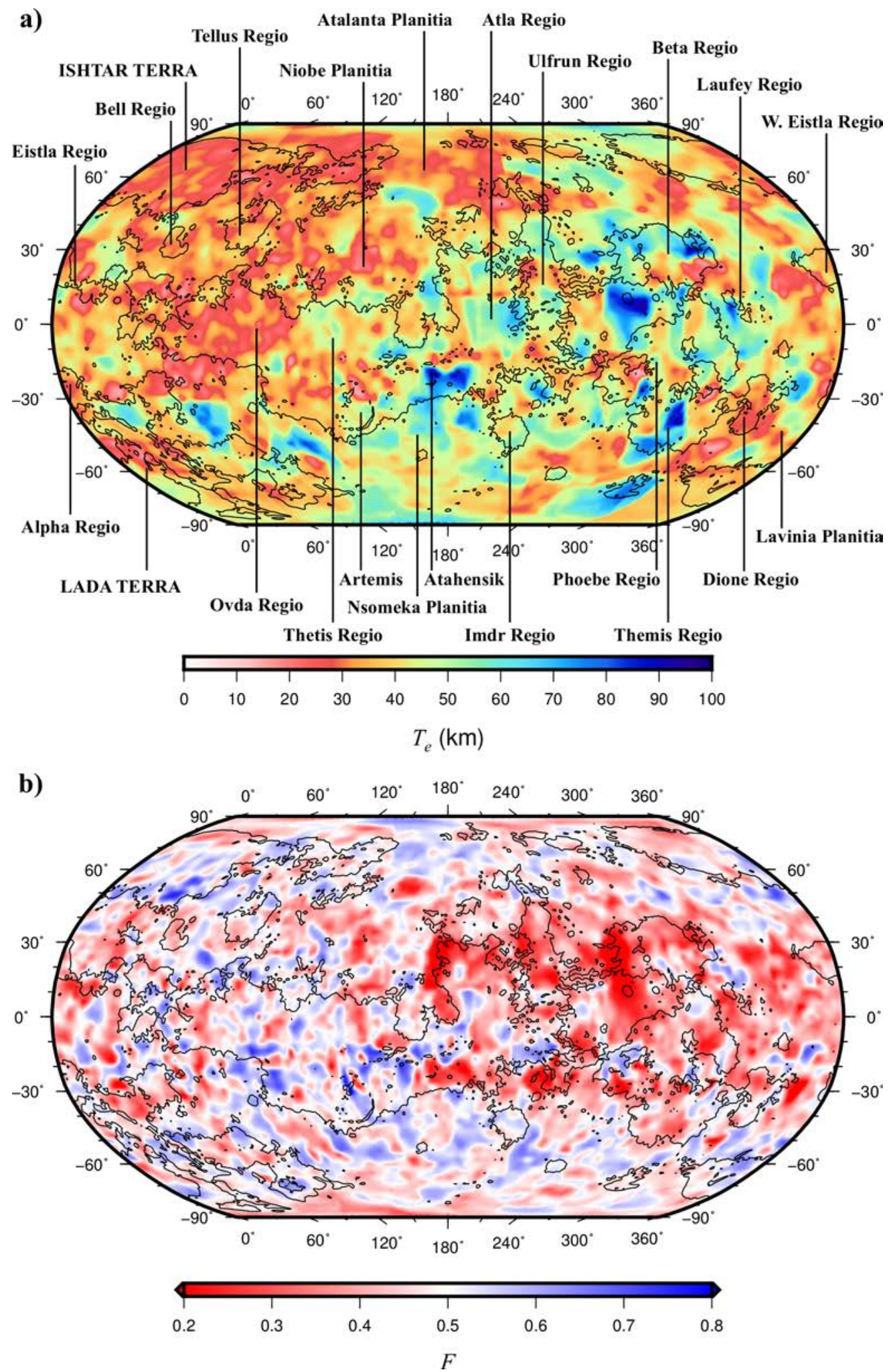

Figure 6. Results of the inversion of the squared-real Bouguer coherency $\left(\left|\mathbf{k}_{0}\right|=5.336\right.$ ). (a) Effective elastic thickness, $T_{e}$. (b) Internal load fraction, $F$, corresponding to the $T_{e}$ results in (a). Black contour is the zero topography contour. 
a)

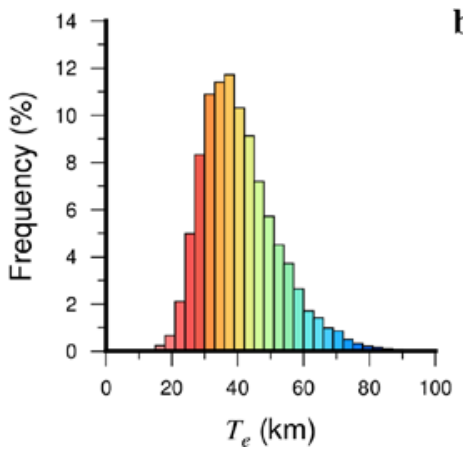

b)

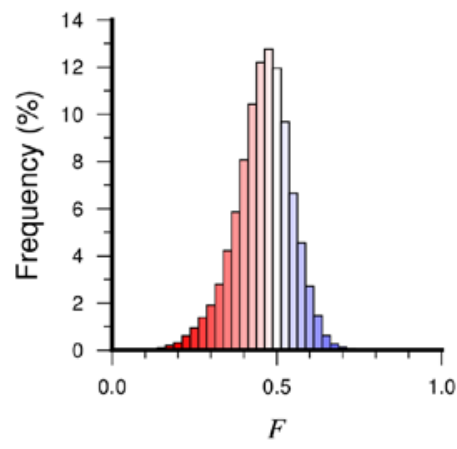

c)

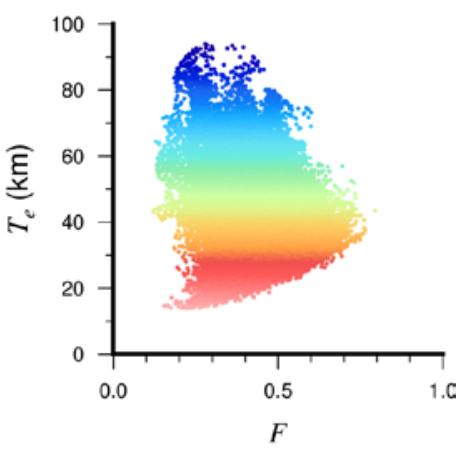

Figure 7. (a, b) Histograms of $T_{e}$ and $F$, corresponding to the results in Fig. 6. Panel (c) shows $T_{e}$ against F. 

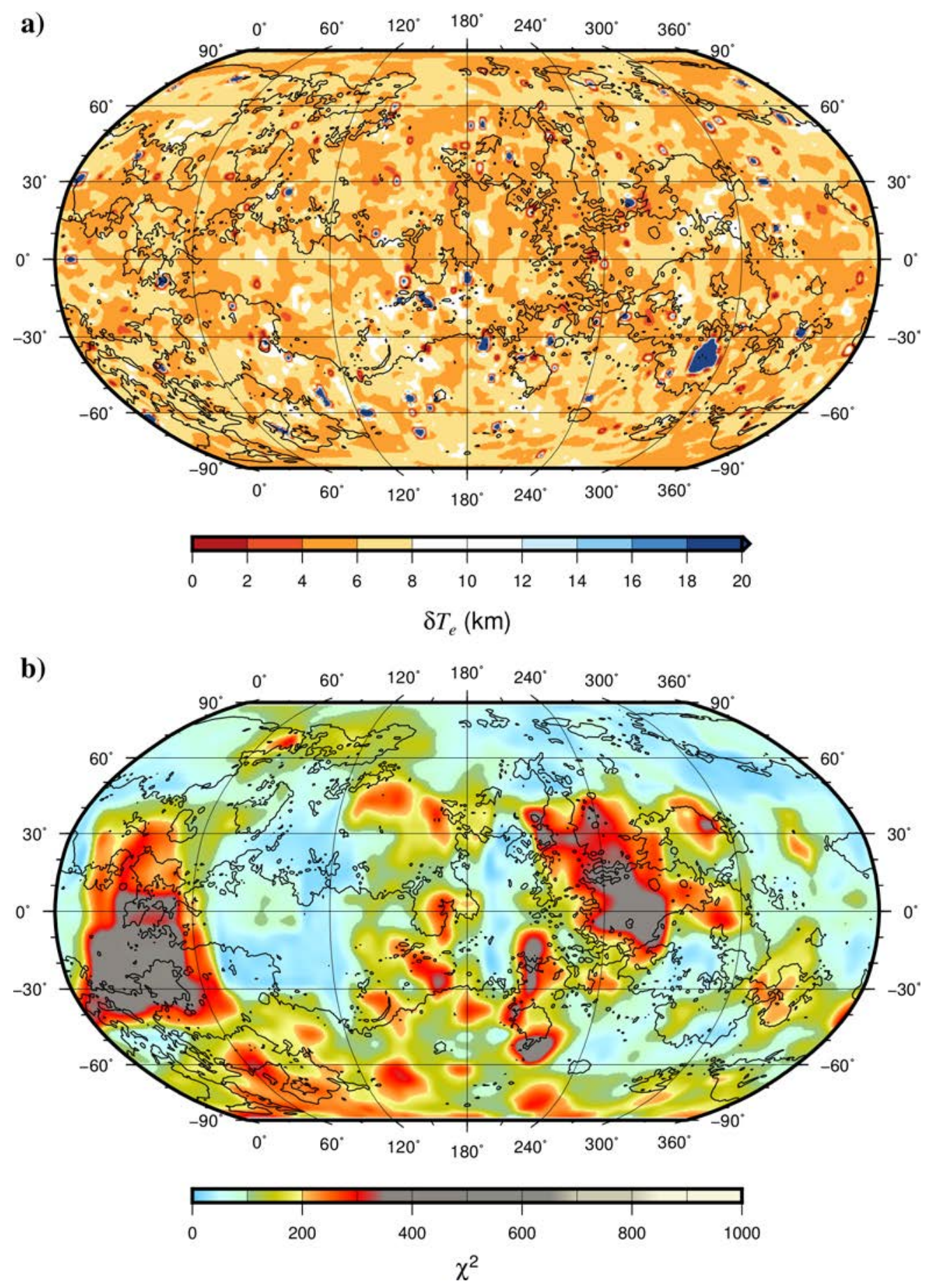

Figure 8. Results of the inversion of the squared-real Bouguer coherency $\left(\left|\mathbf{k}_{0}\right|=5.336\right)$. (a) $T_{e}$ error and (b) chi-squared misfit, corresponding to the results in Fig. 6. Black contour is the zero topography contour. 


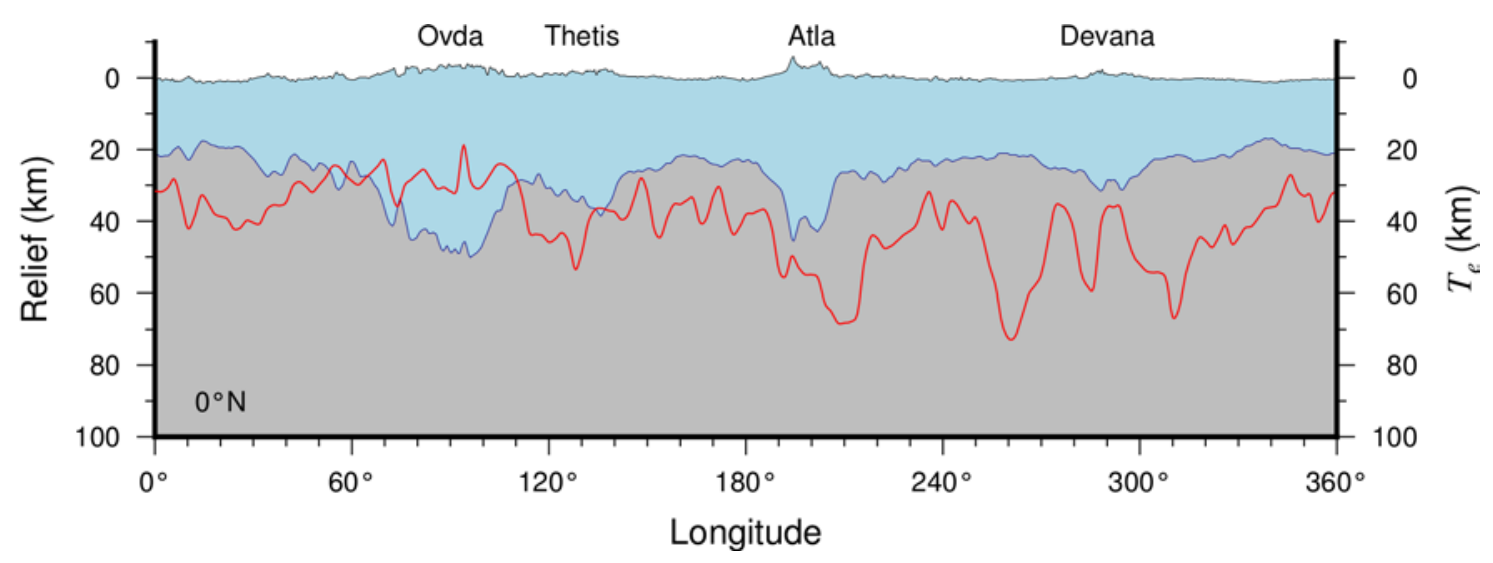

Figure 9. Equatorial transect of our crustal thickness model (figure format is the same as Fig. 4c). The red line corresponds to the variation of the effective elastic thickness (right axis) along the same profile.

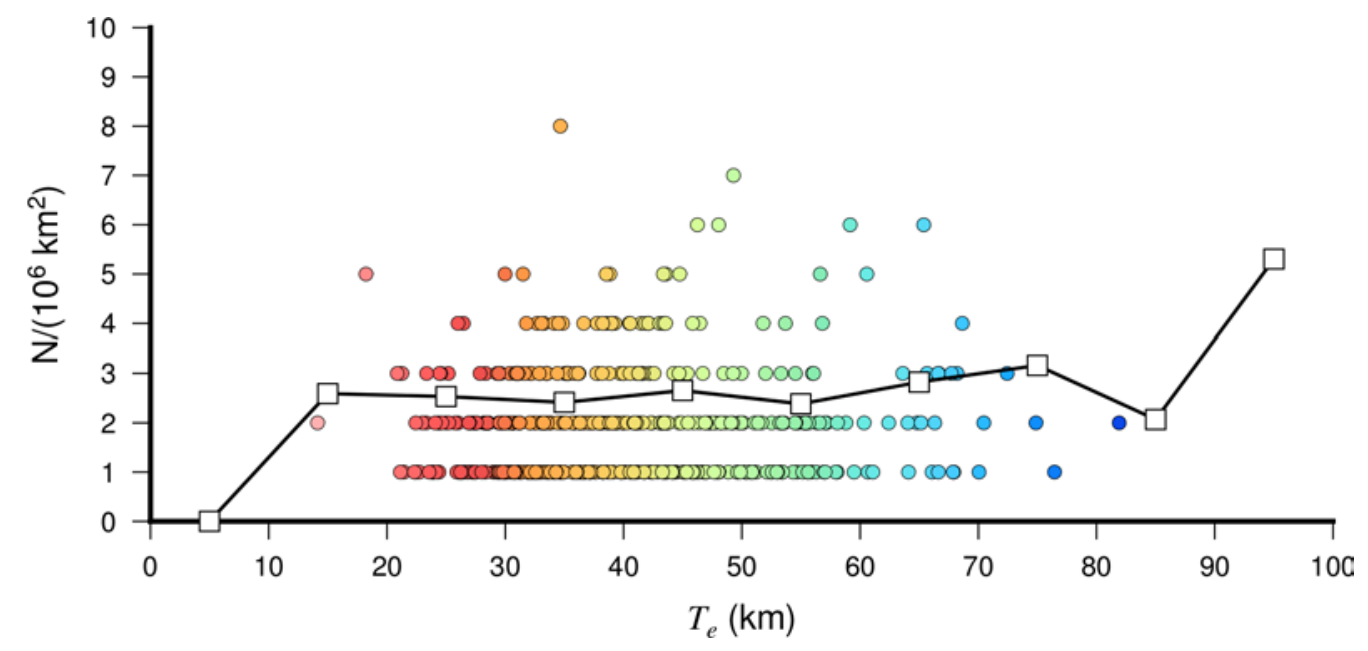

Figure 10. Plot of crater density ( $N=942$; Schaber et al., 1998) obtained with sampling windows of $10^{6}$ $\mathrm{km}^{2}$ against the mean value of $T_{e}$ in each window (points); and crater density calculated counting the number of craters for $T_{e}$ intervals of $10 \mathrm{~km}$ (white squares and black line). 
a) $T_{e}$ and $F$

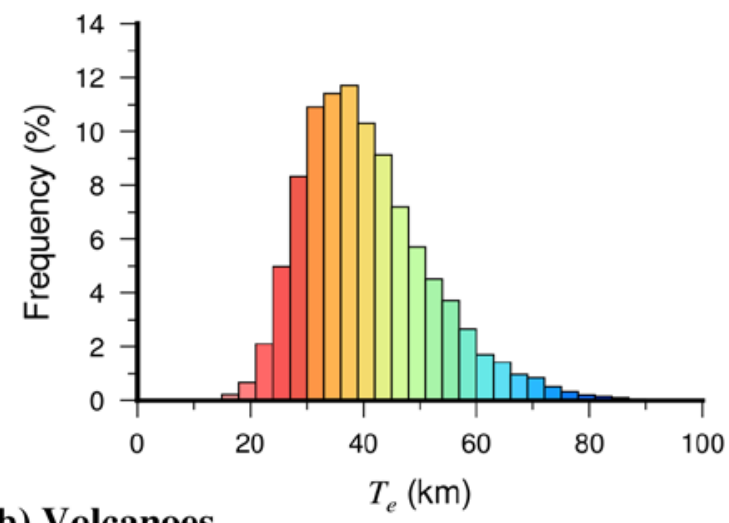

b) Volcanoes

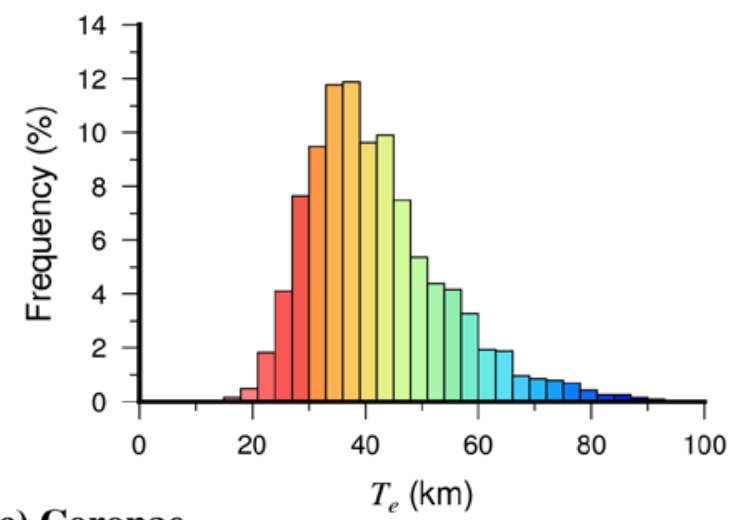

\section{c) Coronae}

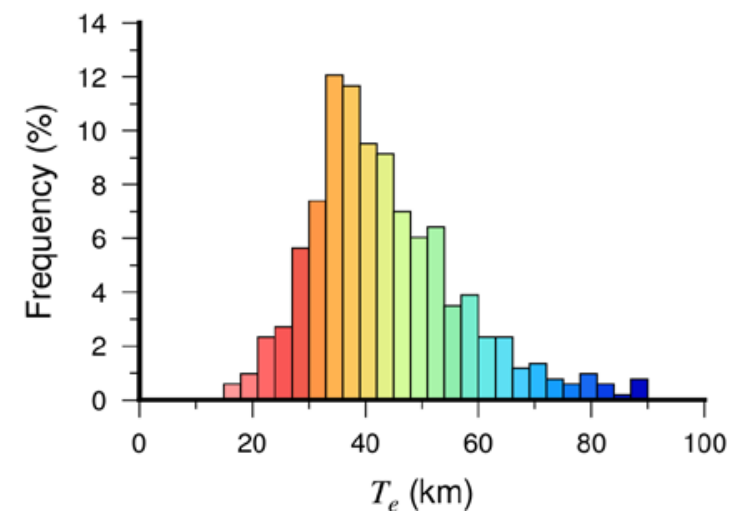

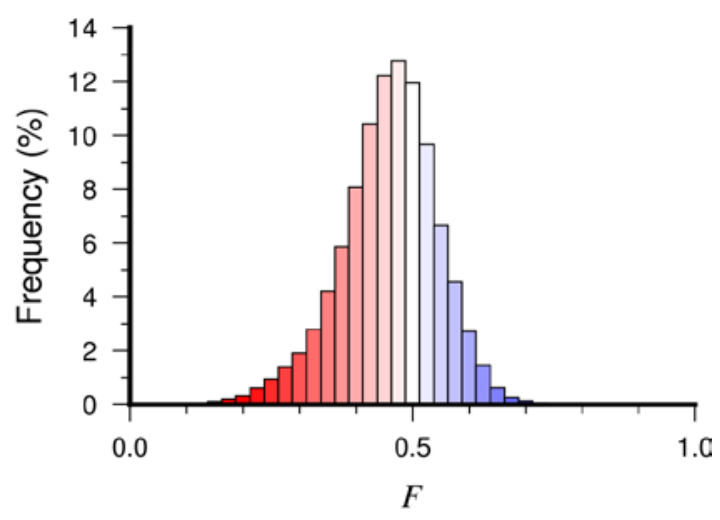
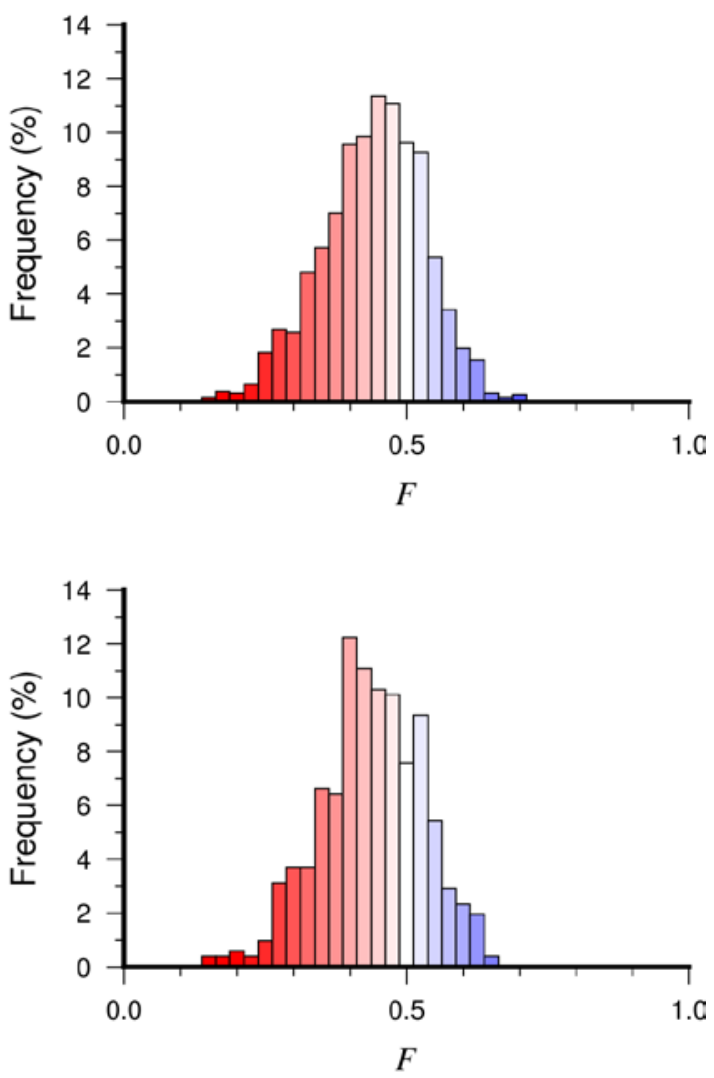

Figure 11. Frequency distributions of volcanoes $(N=1868$; Schaber et al., 1998) and coronae $(N=513$; Stofan et al., 2001) versus $T_{e}$ and $F$ values. (a) Histograms of $T_{e}$ and $F$ frequencies, corresponding to the results in Fig. 6, shown for reference. Histograms of volcanoes (b) and coronae (c) versus $T_{e}$ and $F$. 

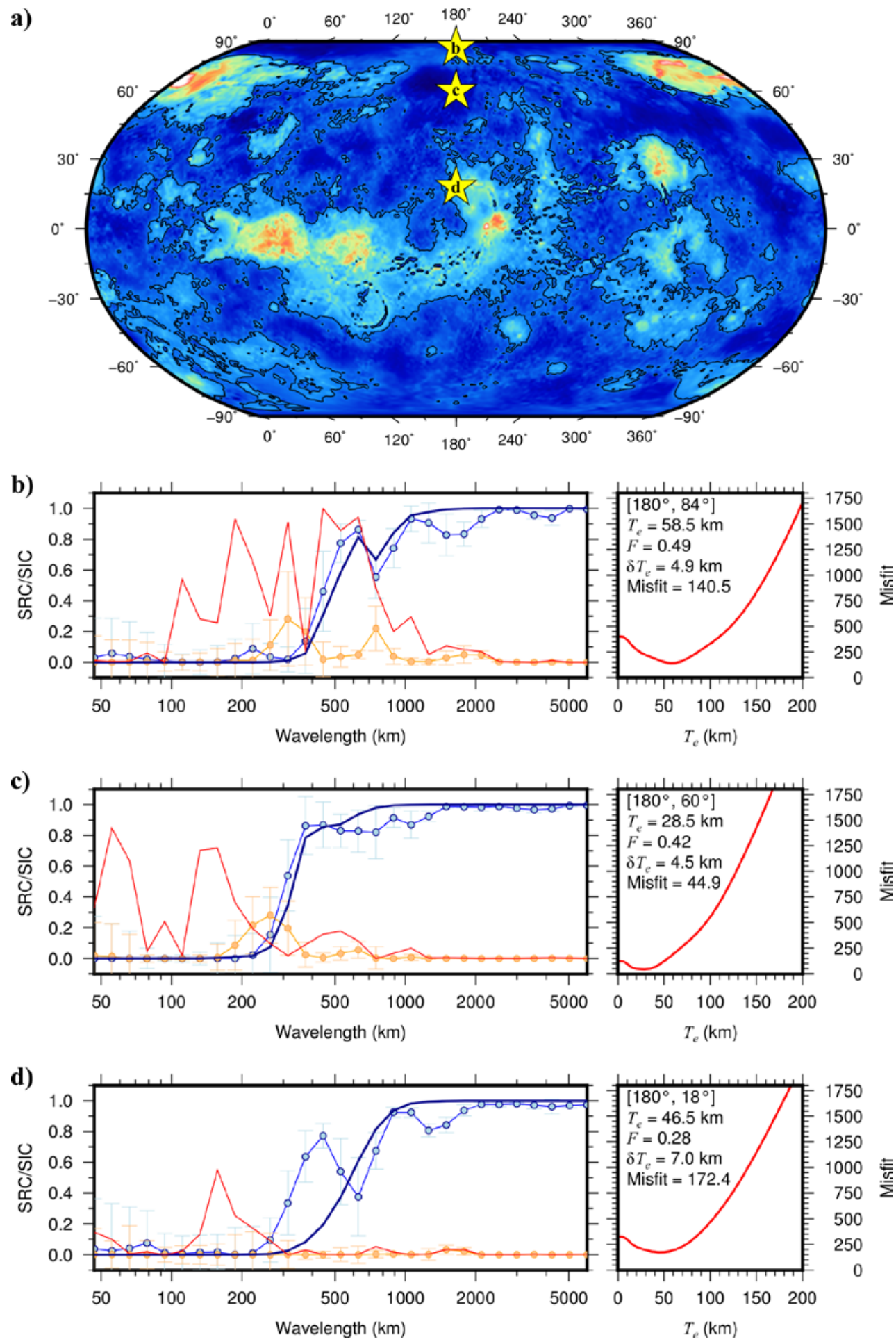

Figure A1. (a) Robinson projection of Venus' topography with $180^{\circ}$ longitude at centre. Black contour is the zero topography contour. Yellow stars indicate the locations of $1 \mathrm{D}$ squared-coherency profiles shown below. (b-d) Example of curve fitting and inversion results using the squared-real Bouguer coherency $\left(\left|\mathbf{k}_{0}\right|\right.$ $=5.336$ ). The autospectra and cross-spectra were averaged over spatial dimensions of $500 \times 500 \mathrm{~km}$ and the observed coherency formed from these. Profiles were inverted only using observations with wavelengths $>211 \mathrm{~km}$. Left panels: The observed squared-real Bouguer coherency (blue circles with their error bars and blue lines); the observed squared-imaginary Bouguer coherency (orange circles with their error bars and orange lines); the best-fitting predicted squared-real Bouguer coherency (dark blue lines); and the observed normalized imaginary free-air coherency (thin red lines). Right panels: misfit curves (thick red lines) used to estimate $T_{e}$ using the squared-real Bouguer coherency; and the values of the best fitting $T_{e}$ and $F$, as well as the value of the $T_{e}$ error and chi-squared misfit at all locations. 
a)

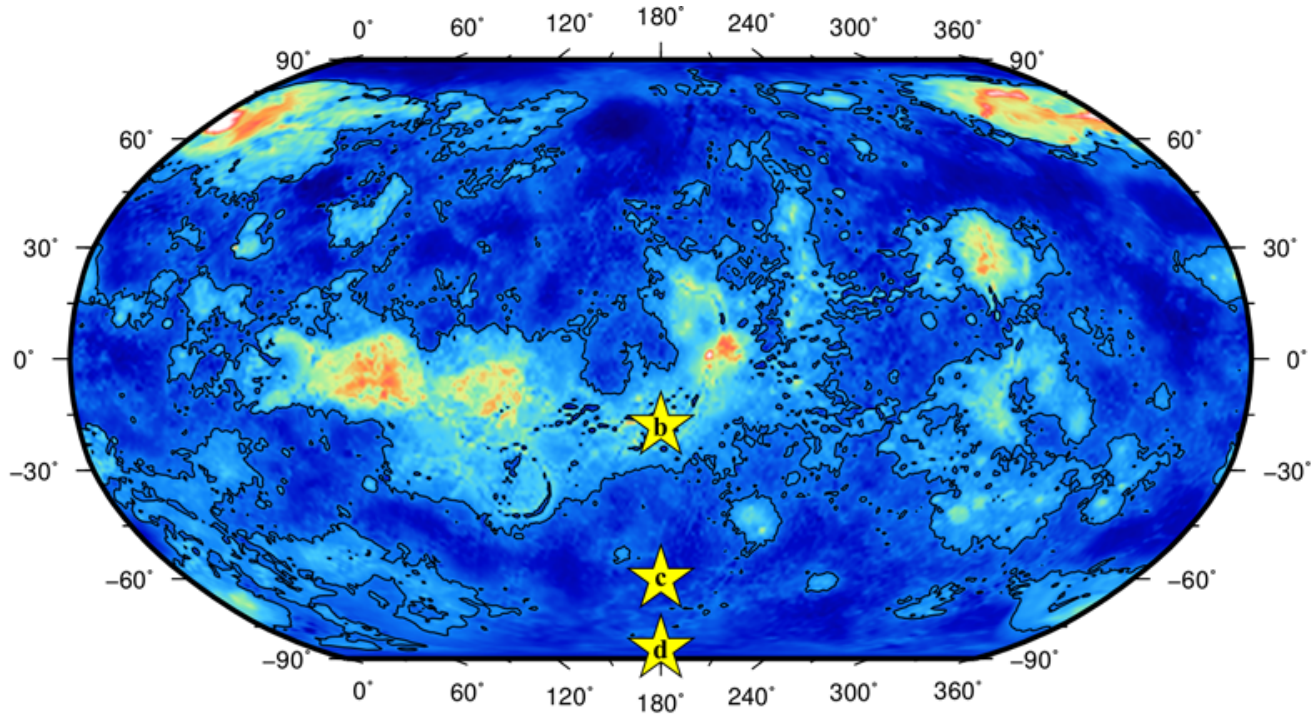

b)
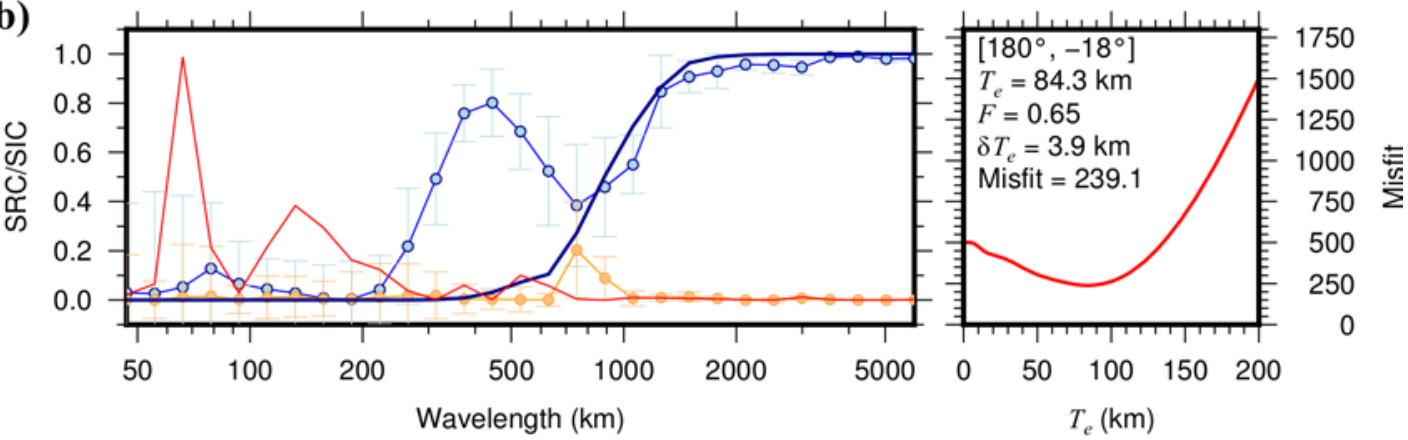

c)
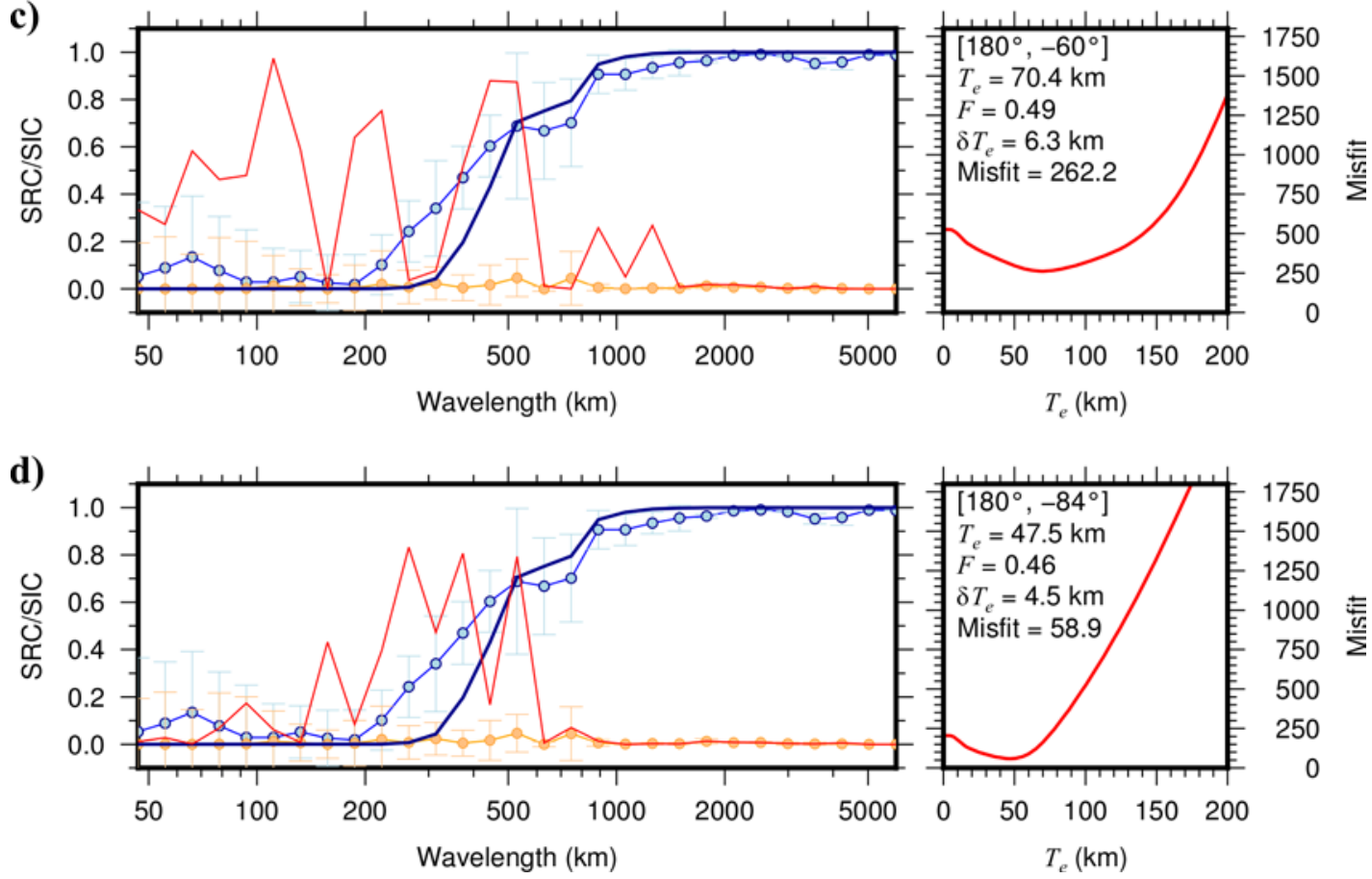

Figure A2. Example of curve fitting and inversion results using the squared-real Bouguer coherency $\left(\left|\mathbf{k}_{0}\right|\right.$ $=5.336$ ). Figure format is the same as Fig. A1. 